\title{
La protéinémie chez la vache
}

\author{
par Cl. LABOUCHE
}

\begin{abstract}
RÉSUMÉ
Le taux des protéines totales, de l'albumıne et des globulınes du sérum sanguin de la vache est une donnée très variable, d'un animai à un autre ef d'un troupeau à un autre.

Ceci provient de l'intervention de facleurs propres aux animaux (race, âge, gestation, lactation), de facteurs d'envıronnement (saison, température, alimentation), mais également, en milieu tropical, des différentes significations que l'on peuf donner ou terme «d'animal normol 》.

On peut retenir pour les protéines totales des chiffres variant de 64,5 à 89.2 g/l pour les animaux tropicaux; pour l'albumine, une valeur moyenne de 30 à $35 \mathrm{~g} / \mathrm{l}$ ef paur les globulines de 50 à $55 \mathrm{~g} / /$ en milieu tropical ef de $40 \mathrm{~g} / \mathrm{l}$ en pays tempéré.

Le rapport albumine/globuline dans ces conditıons aura une valeur approximative de 0,75 en milieu tempéré et de 0,60 en climat tropical, avec de larges variations possibles.
\end{abstract}

Placé au centre de l'activité biochimique de l'organisme, le foie intervient dans l'anabolisme et le catabolisme des grands principes nutritifs, ainsi que dans la plupart des phénomènes de détoxication. Organe délicat, doté de multiples fonctions, il est souvent l'objet d'agressions diverses surtout toxiques et parasitarres, conduisant à des lésions parfois irréversibles.

Aussı, l'étude de la pathogénie de nombre d'affections ou d'intoxications fait-elle souvent appel à l'exploration fonctionnelle hépatique. Dans ce cadre, parmi les tests utilisés, l'appréciation de la teneur du sang en protéines ef la détermination de l'importance relative des différentes fractions protéiques sont souvent mises à contribution.

Cependant, les renseignements fournis par ces méthodes ne prennent leur véritable sens que si on peut les comparer à des valeurs de référence obtenues chez l'animal normal. En médecine vétérinaire, et plus particulièrement chez les grands Ruminants, le nombre de ces données de base est encore relativement limité et l'intervention de facteurs extérieurs ou propres à l'animal provoque de larges variations.

Dans quelle mesure interviennent ces agents perturbateurs ? Que faut-il entendre par protéinémie normale? Nous avons cherché à répondre à ces questions, en rapprochant des observations publiées jusqu'ici en climat tempéré ou tropical, les travaux menés, chez la Vache, au cours de ces dernières années au Laboratoire national de Recherches Vétérinaires à Dakar (LABOUCHE et Coll., 1963 a, b, c).

Les animaux du Centre de Recherches agronomiques de Bambey et ceux de la ferme-annexe du Laboratoire à Sangalkam ont servi à nos travaux. Le premier troupeau comporte 26 animaux (20 N'Damas ef 6 Zébus) et le second 12 craisés Zébu $\times$ N'Dama. La base de l'alimentation éfait constituée par le pacage en brousse, mais les vaches de Sangalkam ont également bénéficié d'une distribution quotıdienne de tourteau d'arachide déshuilé aux solvants. La durée 
des observations a été d'un an, le début se sıtuant en fin de saison sèche (1).

Nous envisagerons successivement les points suivants :

- remarques concernant la détermination des protéines sériques par électrophorèse,

- les protéines sériques totales,

- l'albumine sérique.

- les globulines totales,

- le rapport albumine/globuline.

\section{I. - REMARQUES CONCERNANT LA DÉTER- MINATION DES PROTÉINES SÉRIQUES PAR ÉLECTROPHORĖSE CHEZ LES RUMI- NANTS.}

Depuis une dizaine d'années, les techniques d'électrophorèse - et, en particulier, celles utilisant comme support le papier - connaissent un large succès que justifient leur simplicité ef la mise au point d'appareils automatiques d'interprétation quantitative.

Néanmoins, la délimitation des courbes gaussiennes ef la mesure de leur surface peuvent être entachées d'erreurs appréciables. Le tracé à main levée manque forcément de précision, et les intégrateurs automatiques apprécient des surfaces qui ne sont pas toujours égales à celles des courbes de Gauss constituant le diagramme d'électrophorèse.

Pour pallier ces insuffisances, une méthode mathématique d'exploitation quantitative a été proposée (LABOUCHE, 1962 a). Elle permet de reconstituer de proche en proche une courbe de Gauss, à la condition d'en connaître deux points, dont le sommet. Un calcul simple, ne nécessitant pas le tracé de la courbe, permet également de mesurer, avec précision, les surfaces. Cependant, cette méthode n'est exploitable que si les fractions sont suffisamment isolées les unes des autres.

Malheureusement, I'électrophorèse - en milieu liquide ou sur papier - ne nous a pas donné de bons résultats chez les Ruminants tropicaux avec les nombreux tampons que nous avons

(1) Dans la presqu'île du Cap Vert, la saison des pluies (hivernage) s'étend du début de juillet à la fin de septembre. Les pluies apparaissent plus tôt à Bambey qu'à Sangalkam. La station de Bambey est de fype sahélien ; celle de Sangalkam est sifuée dans la zone subguinéenne de la presqu'île (régıon des Niayes). utilisés (Rapport1959-1960 du Laboratoire de l'Elevage, Dakar), et l'examen des travaux publiés jusqu'ici laisse à penser que le problème n'est pas encore résolu d'une manière satisfaisante. Dans certains cas, les clichés d'électrophorèse n'ont pas été reproduits. Dans d'autres, on assiste à une prolifération de pics dont certains pourraient être considérés comme de simples Irrégularités de tracé. Enfin, de rares auteurs vont jusqu'à repérer des fractions dont les pics sont indiscernables.

Effectuer une interprétation quantitative dans ces conditions nous a paru, à priori, contestable, et nous avons alors évalué l'erreur qui accompagne les séparations incomplètes (LABOUCHE, 1962 b) lorsque la mesure des surfaces est effectuée par une des méthodes suivantes:

- tracé à main levée du contour des courbes et mesure planimétrique,

- méthode mathématique de délimitation des courbes et de détermination des surfaces,

- utilisation des intégrateurs automatiques.

Quatre courbes gaussiennes, mathématiquement définies, de surfaces connues et que l'on fait mutuellement se chevaucher, ont servi à édıfier des électrophorégrammes artificiels que l'on redécompose par une des méthodes précédentes. On compare alors les résultats obtenus à la valeur réelle. Il est alors possible de constater:

- que lorsque l'empiétement des courbes ne provoque pas de modification de la hauteur des sommets, la mesure de la surface des fractions alpha ef béta se fait avec une approximation pouvant atteindre \pm 30 p. 100.

- que lorsque l'ordonnée des sommets est perturbée, la méthode manuelle est, par essence, systématiquement fausse. L'erreur relative liée à la méthode mathématique s'amplifie tandis que l'intégration automatique conduit à des données très approximatives.

Il est à souligner que, dans tous nos,modèles, les pics sont restés individualisés. Or, dans la pratique, le sommet alpha est souvent inapparent et le sommet béta n'arrive pas à s'isoler du versant des gamma-globulines. Il paraît done sage, dans ces conditions, de n'accorder aux chiffres donnés par l'électrophorèse du sérum des Bovidés qu'une confiance limitée.

Nous avons alors voulu tourner la difficulté 
en essayant de reconstituer, lors de séparations incomplètes, les différentes courbes en utılisant deux points quelconques pris sur des portions non perturbées des diagrammes d'électrophorèse. Les bases mathématiques d'un tel procédé ont été jetées ( $\mathrm{AABOUCHE}, 1962 \mathrm{C}$ ). Cependant, cette méthode n'est pas exploitable dans la pratique ; les abcisses des points de référence demandent, en effet, à être connues avec une précision au moins égale ò $10^{-2} \mathrm{~mm}$, ce qui paraît, à première vue, dépasser à la fois la sensıbilité et la fidélité des densitomètres habitueis ( $L A B O U C H E, 1962 d$ ).

En conséquence, l'électrophorèse quantitative du sérum des Ruminants naus parassant aléatoire, nous nous sommes rabattus sur une méthode classique, celle par précipitation par le sulfate d'ammonium à demi-saturation suivie du dosage colorimétrique basé sur la réaction du biuret, qui permet de suivre avec sécurité l'action des différents facteurs susceptibles d'agir sur la protéinémie, bien que ne réalısant qu'un fractionnement rudimentaire.

Dans le même esprit, au cours de nos recherches bibliographiques, nous avons surtout retenu les donnéeśs obtenues par les techniques de précipitation.

\section{II. - LES PROTÉINES SÉRIQUeS TOTALES (PST)}

\section{a) La protéinémie moyenne}

La moyenne générale détermınée pour l'ensemble de nos observations est de $86,7 \mathrm{~g} / 1$ de sérum pour les animaux de Bambey et de $86,0 \mathrm{~g} / 1$ pour ceux de Sangalkam. Ces deux valeurs sont très proches malgré des conditions d'entretien différentes.

Les valeurs moyennes publiées jusqu'ıci par d'cutres auteurs sont rassemblées dans le tableau I. Ces données varient dans de larges limites : de $64,5 \mathrm{~g} / \mathrm{l}$ (de FRANCISCIS, 1957) da 89,2 g/l (HEYNDRICKX, 1959) en milieu tempéré et de 59,1 (ROSS, 1960) à 78,8g/l (GARNER, 1950) en climat tropical. Les protéinémies moyennes dans la presqu'île du Cap Vert se rapprochent donc des concentrations les plus élevées de climat tempéré ; elles dépassent très sensıblement les teneurs récemment publiées en Gambie (WALSHE ef GILLES, 1962).

\section{b) Les variations individuelles de la protéinémie}

Ces variations ont été exprimées, pour chaque mols de l'année, en exprimant l'écart-type en pourcentage de la moyenne correspondante. Le tableau III résume nos résultats et le tableau II ceux calculés à partir des chiffres trouvés dans la littérature.

Pour ces derniers, ce coefficient de variation varie de 2,8 à 17,7 p. 100 , mais la plupart des valeurs se regroupent entre 8 et 10 p. 100 . Parfois la dispersion est faible (5 p. 100) ; it peut s'agir de lots d'animaux très homogènes ou bien, plus simplement, d'une confusion entre l'écart-type et l'écart type de la moyenne, car dans nombre de publications cette précision n'est pas apportée.

En définitive, on peut estimer que les PST d'un animal normal pris au hasard a de très grandes chances de se trouver dans une zone de \pm 15 à 20 p. 100 de la valeur moyenne correspondante.

\section{c) Les variations saisonnières de la protéinémie}

La concentration sanguine en PST subit des modifications au cours de l'année. Chez nos animaux, elle varie de 80,4 à $92,5 \mathrm{~g} / \mathrm{l}$ à Sangalkam ef de 83,5 d̀ 91,3 g/l à Bambey. Les teneurs les plus élevées sont notées au début et les plus faibles à la fin de la saison sèche. L'apparition des précipitations s'accompagne d'un enrichissement en protéines du sérum. Cet enrichissement est transitoire et, en fin d'hivernage, des valeurs relafivement basses sont rencontrées. La fin des pluies coincide avec une nouvelle ascension et, à la fin de l'année, des concentrations élevées sont relevées (tableau III).

L'éfude statistique prouve la réalité d'une relation de type parabolique entre la protéinémie ef le temps, en début de saison sèche. L'évolution porte sur six mois à Sangalkam et sur quatre mois à Bambey.

Une influence de la saison sur la concentration en PST avait déjà été signalée, avant nos observations. En milieu tempéré, WEHMEYER (1954 c) rapporte une augmentation au printemps ; celle$\mathrm{Cl}$ se maintient jusqu'en hiver puls se stabilise à un niveau plus bas. En milieu tropical, les opinions divergent. MULLICK et PAL (1943), en Inde, considèrent stables les PST (72 à $75 \mathrm{~g} / \mathrm{l})$. En Australie, BARNES et JEPHCOTT (1959), après avoir comparé les protéinémies mesurées 
TABIRAT NO I

Tanx moyens des protéines totales du sérum de bovicés

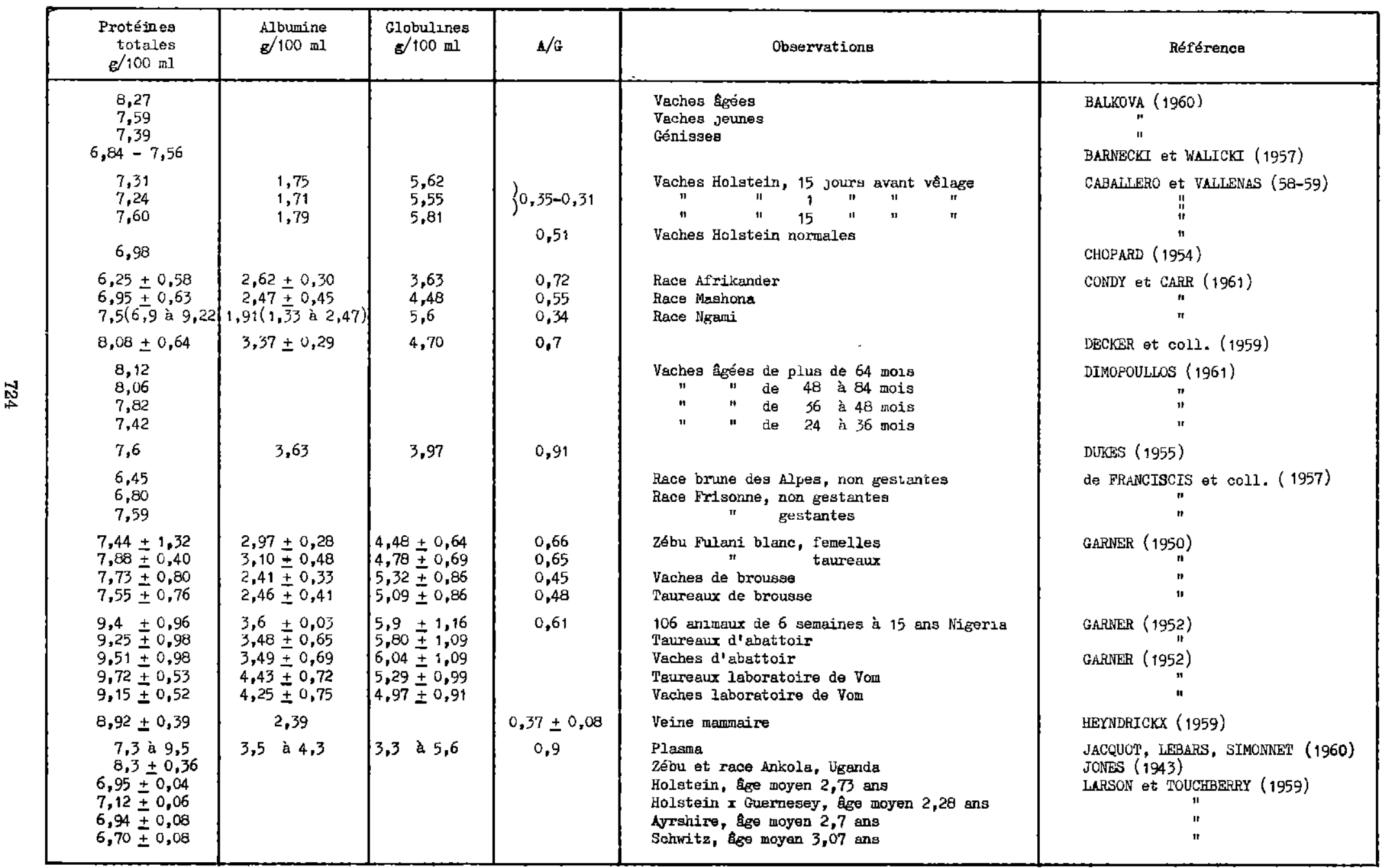


TABLEAU NO I (suite)

Taux morens des protóines totales du gérum de bovldás

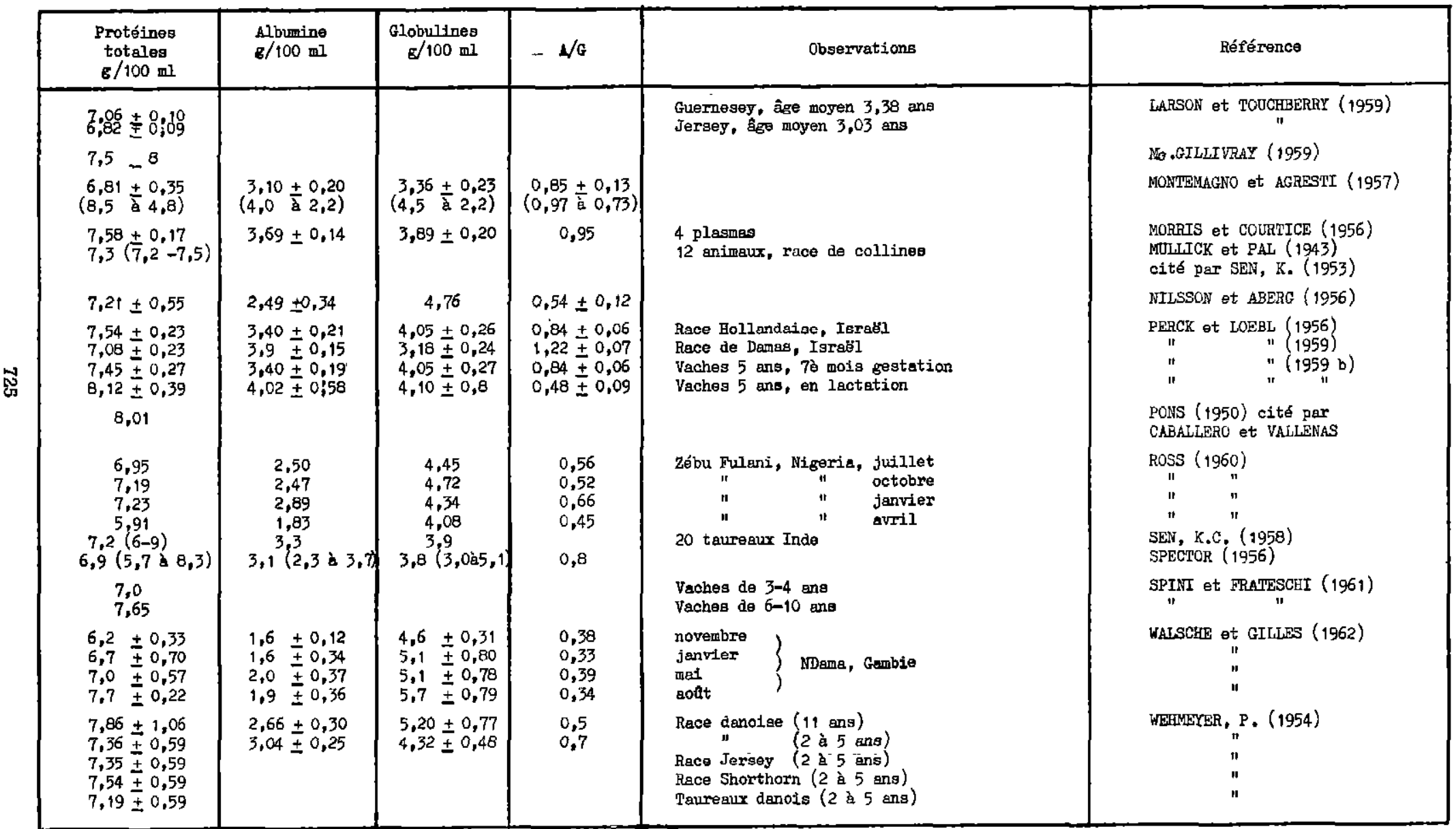


TABLEAUU No II

Coefficients de variation cslculés a partir de données publiées par différents auteurs.

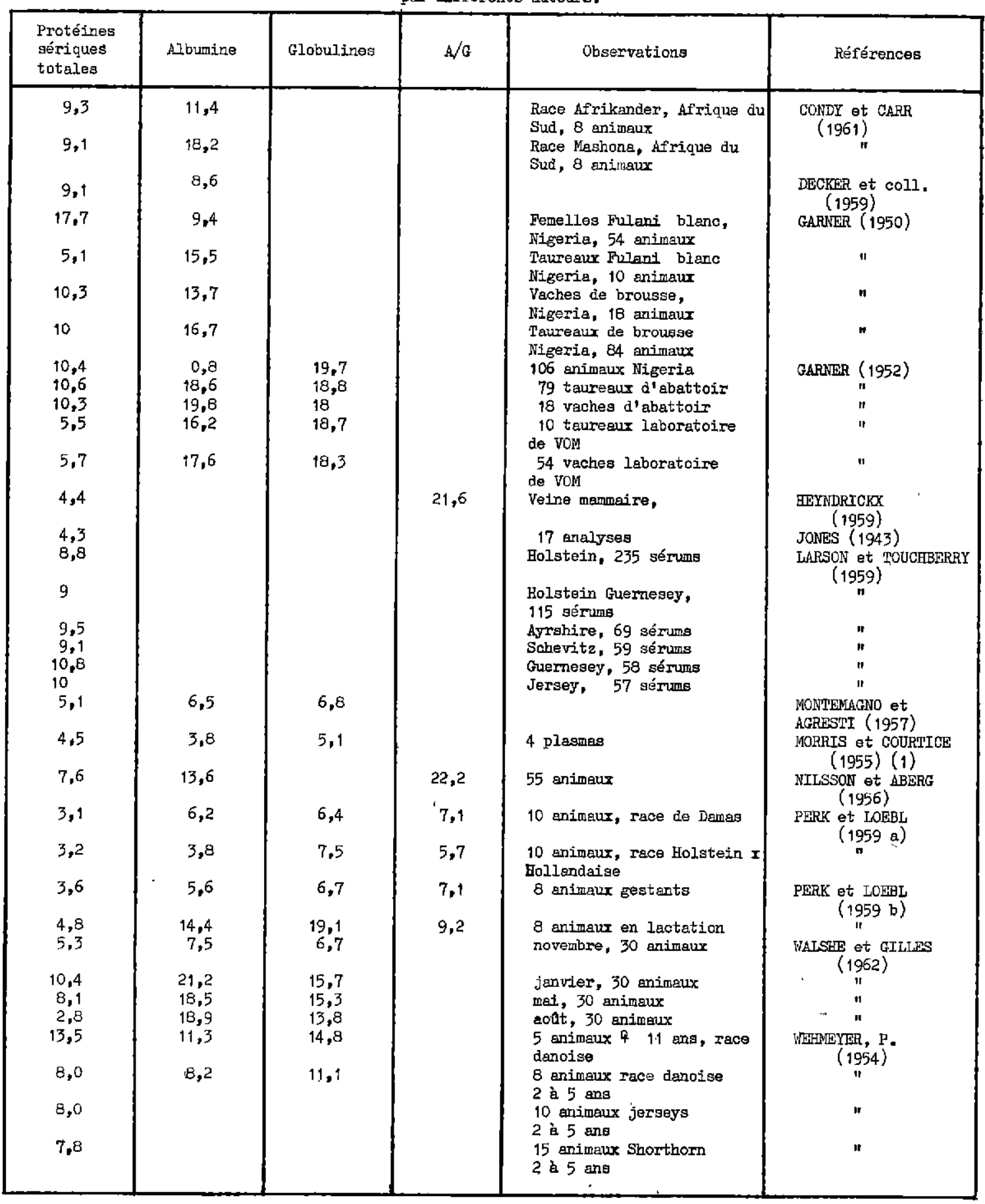


TAELAU $\mathrm{X}$ O III

Valeurs moyennes des protónines sériques totales dour les troupeaux SGK et $B B$

\begin{tabular}{|c|c|c|c|c|}
\hline \multicolumn{3}{|c|}{ Troupeau S G k } & \multicolumn{2}{|c|}{ Troupean B B } \\
\hline Noisa & $\begin{array}{c}\text { Protéznes totales } \\
\mathrm{g} / \mathrm{litre} \\
\pm\end{array}$ & $\begin{array}{l}\text { Coefficient } \\
\text { de } \\
\text { variation }\end{array}$ & $\begin{array}{l}\text { Protéines totales } \\
\text { g/litre } \\
\pm\end{array}$ & $\begin{array}{l}\text { Coefficlent de } \\
\text { varzation }\end{array}$ \\
\hline mars & $82,5 \pm 3,7$ & 4,5 & & \\
\hline avril & $81,5 \pm 4,0$ & 4,9 & $84,6 \pm 5,5$ & 6,5 \\
\hline mar & $82,9 \pm 4,2$ & 5,0 & $83.5 \pm 4.9$ & 5,9 \\
\hline תشار. & $83.8 \pm 3.6$ & 4.3 & $89,4 \pm 5,7$ & 6,4 \\
\hline Jucilet & $83,2 \pm 5,9$ & 7,1 & $85,1 \pm 5,8$ & 6,8 \\
\hline août & $86,4 \pm 4,5$ & 5,0 & $87,7 \pm 5,7$ & 6,5 \\
\hline septembre & $80,4 \pm 3,4$ & 4,2 & $85,9 \pm 5,5$ & 6,5 \\
\hline octobre & $89.4 \pm 4.5$ & 5,1 & $8 \overrightarrow{6} \pm 4,0$ & 4,7 \\
\hline novembre & $90,9 \pm 3,5$ & 3,8 & $91,3 \pm 5,8$ & 6,4 \\
\hline décerabre & $91,9 \pm 4,8$ & 5,2 & $91,3 \pm 5.1$ & 5,5 \\
\hline Janvier & $92,5 \pm 5,9$ & 6,4 & $87,5 \pm 4,4$ & 5,0 \\
\hline fóvrier & $87,5 \pm 4,2$ & 4.8 & $89,5 \pm 5,3$ & 6,3 \\
\hline mars & & & $87,2 \pm 5,1$ & 5,8 \\
\hline avril & & & $84,7 \pm 5,8$ & 6,8 \\
\hline
\end{tabular}

à 8 mois d'intervalle sur 50 animaux, ne trouvent pas de différence significative entre les valeurs moyennes $(77,0 \mathrm{~g} / \mathrm{l}$ et $77,7 \mathrm{~g} / \mathrm{l})$. Par contre, en Nigeria, ROSS (1960) rencontre des valeurs faibles en fin de saison sèche $(59 \mathrm{mg} / \mathrm{l}$ en avril) et des chiffres plus élevés en saison des pluies ( $69,5 \mathrm{~g} / \mathrm{l}$ en juillet; $71,9 \mathrm{~g} / \mathrm{l}$ en octobre). II en est de même en Gambie (WALSHE et GILLES, 1962).

\section{d) Influence de l'alimentation sur le taux de PST}

Certains auteurs voient dans les variations saisonnières des PST le résultat de modifications de lu composition de la ration (ROSS, 1960 ; WALSHE ef GILLES, 1962). Pour CHOPARD (1954), en Suisse, les PST augmentent lors du passage du foin à l'herbe. MENON et REDDY (1960), en Inde, estiment qu'à une ration pauvre en protéines correspond un taux diminué de PST.

Cependant, BARNES ef JEPHCOTT (1959) nient une intervention alimentaire éventuelle ef CZAJA et JAROWSKI (1959), chez le veau, ne trouvent pas de relation entre l'azote total du sérum et l'azote de la ration.

L'interprétation de nos chiffres sous l'angle des modifications du régime est délicate. Ainsi, la distribution de tourteau d'arachide ne rend pas la courbe de protéinémie de Sangalkam significatıvement différente de celle de Bambey. Par contre, l'augmentation de l'azote de la matière sèche des fourrages en début de saison sèche (résultats non publiés), entraînant la consommation d'une plus grande quantité d'azote, pourrait être à l'origine de l'accroissement des PST à cette période de l'année. Cependant le maximum observé en début de saison des pluies est plus difficılement interprétable. II est vraisemblable que l'influence alimentaire représente la résultante de deux facteurs : le rapport azote/ indigestible qui conditıonne l'ingestion d'azote et le rapport azote/hydrocarbones qui règle les modalités de l'utılisation azotée en particulier au niveau de la panse.

\section{e) Influence de la température ambiante}

Les variations de la température extérieure pourraient aussi constifuer un des facteurs de la variation salsonnière des PST. DIVEN et Coll. (1958) signalent pour des températures de 27 , $32,35,3^{\circ} \mathrm{C}$ des protéinémies de 62,68 et $107 \mathrm{~g} / \mathrm{l}$. 
Ils notent également des variations parallèles des PST et de la température extérleure dans le courant d'une même journée. WEHMEYER (1954 c) rapporte également des fluctuations quotidiennes de la protéinémie.

A Dakar, sur 9 anımaux en stabulation et avec des prélèvements effectués le même jour à 9,11 . 15 et 19 heures, la température variant de $21,3^{\circ} \mathrm{C}$ à $28,6^{\circ} \mathrm{C}$, les résultats suivants ont été obtenus :

$\begin{array}{cc}\text { Température } & \text { PST } \\ { }^{\circ} \mathrm{C} & \underline{\mathrm{g} / \mathrm{l}} \\ 21,3 & 77,2 \\ 24,1 & 78,8 \\ 27,9 & 79,1 \\ 28,6 & 84,6\end{array}$

Le coefficient de corrélation est positif et signıficatif $(r=+0,36 ; P=0,03)$. Par contre, une autre expérience effectuée sur les mêmes animaux entre 23,7 et $25,4^{\circ} \mathrm{C}$ s'est soldée par un échec. L'écart de température dans ce deuxième essai était sans doute insuffisant.

Le facteur thermique n'est cependant pas le seul agent de variation saisonnière des PST. S'il en était ainsi, on devrait observer des courbes plus ou moins parallèles pour la température et pour les PST. Or, il n'en est rien : la température à Bambey augmente progressivement d'auril d̀ août puis diminue lentement jusqu'en janvier (1).

\section{f) Influence de l'âge}

Le taux des PST augmente à mesure que I'animal vieillit (BALKOVA, 1960 ; DIMOPOULLOS, 1961 ; PERK ef LOEBL, 1959 b, SPISNI ef FRATESCHI, 1961) et se stabilise vers l'âge de 4 ans (LARSON et TOUCHBERRY, 1959) ou de cinq ans (GARNER, 1960). Nos observations confirment ces données mais font apparaître également une interférence du facteur saisonnier dans les valeurs respectives des protéinémies d'animaux d'âges différents (tableau IV).

\section{g) Influence du sexe}

Peu d'investigations ont été effectuées dans ce domaine. Pour GARNER (1960) le sexe n'intervient pas, tandis que EDWARDS (1944) constate

(1) Les tempérofures moyennes mensuelles entre avril el mars de l'année suivante ont été : 15,$6 ; 17,6 ; 20,4$; 23,$4 ; 23,6 ; 21,8 ; 20,7 ; 16,9 ; 15,8 ; 13,8 ; 14,2 ; 15,3$ ०C (températures relevées à 8 heures). une différence sensible entre animaux de sexes différents $(75 \mathrm{~g} / \mathrm{l}$ chez la vache et $95 \mathrm{~g} / \mathrm{l}$ chez le taureau).

\section{h) Influence de la race}

Dans le troupeau de Bambey, la protéinémie des N'Damas est significativement supérieure à celle des Zébus pendant l'hivernage et la première partie de la saison sèche. Pendant le reste de l'année, la relation s'inverse mass les différences observées ne sont plus significatives (tableau IV).

En Israèl, la protéınémie des Holstein XHollandaises est supérieure à celle des vaches Damascènes $(75,4 \mathrm{~g} / /$ contre $70,8 \mathrm{~g} / \mathrm{l}$ ) (PERK et LOEBL, 1959 a). En Afrique du sud, des différences ont été rapportées entre les races Afrikander (62,5 $\mathrm{g} / \mathrm{l})$, Mashona $(69,5 \mathrm{~g} / \mathrm{l})$ et N'Gami $(75 \mathrm{~g} / \mathrm{l})$ (CONDY et CARR, 1961).

\section{i) Influence de la gestation}

\section{I) Modifications liées à l'état de gesfation.}

La gestation perturbe le taux de PST, mais le sens de la modification ainsi provoquée varie suivant les auteurs.

En milieu tempéré, l'avortement s'accompagnant d'une augmentation rapide des PST (LARSON et KENDALL, 1957), on pourrait envisager, en première analyse, que la présence du fœtus. s'accompagne d'une diminution de la protéinémie. Pour WEHMEYER (1959 c) et ROSSI (1957) la gestation est inefficace. Par contre, de FRANCISCIS et Coll. (1957) signalent une augmentation chez la vache hollandaise. D'après GERUSOV (1958), l'accroissement des PST persiste quelques semaines après le part.

En Israel, PERK et LOEBL (1959 b) mentionnent une action hyperprotéinémiante de la gestation ; cependant, la comparaison est faite avec des animaux non gestants de trois ans qui n'ant donc pas atteint le taux maximum de PST. En Nigeria, on note une augmentation non significative (6 à $13 \mathrm{~g} / \mathrm{l}$ ) plus importante en saison sèche qu'en saison des pluies.

Au Sénégal, nous avons également constaté une influence saisonnière : la protéinémie des gestantes est supérieure pendant l'hivernage et le début de la saison sèche; les écarts ne sont plus significatifs pendant le reste de l'année (†ablecu IV). 
TABLEAU NOIV

Influence de l'âge, de la race, de la gestation et de la lactation sur le taux de protéines sériques totales, en egramne par litre

\begin{tabular}{|c|c|c|c|c|c|c|c|c|c|c|}
\hline \multirow{3}{*}{ Mois } & \multicolumn{4}{|c|}{ Influence de 11 âge } & \multicolumn{2}{|c|}{ Influence de la race } & \multirow{3}{*}{ Influence de } & \multirow{3}{*}{$\begin{array}{c}\text { 1a gestation } \\
\text { non } \\
\text { gestantea }\end{array}$} & \multicolumn{2}{|c|}{ Influence de la lactation } \\
\hline & \multicolumn{2}{|c|}{ Sangalkam } & \multicolumn{2}{|c|}{ Bambey } & \multirow{2}{*}{ N'Dema } & \multirow{2}{*}{ Zébus } & & & en & \\
\hline & 7 ans & 3 ans & $10-13$ ans & $4-6$ ans & & & & & & \\
\hline mare & 82,5 & 71,4 & - & - & - & - & - & - & - & - \\
\hline avril & 84,5 & 74 & 83 & 87.4 & 85,1 & 83.3 & 84,6 & 85,9 & 87,4 & 87,4 \\
\hline $\operatorname{mat}$ & 82,9 & 72,4 & 81,8 & 83,7 & 82,8 & 85,8 & 82,8 & 82,9 & 82,9 & 84.6 \\
\hline jwin & 83,8 & 75 & 89,6 & 87,6 & 88,5 & 92.3 & 86,1 & 88,4 & 85,4 & 91 \\
\hline juillet & 83,2 & 78,9 & 84,7 & 85,8 & 86,3 & 84,5 & 85,7 & 83,9 & 84,7 & 87 \\
\hline aolet & 86,4 & 77,1 & 89,8 & 87 & 88,3 & 85,6 & 89 & 85,6 & 83.7 & 90,2 \\
\hline septembre & 80,4 & 71,2 & 85,5 & 84 & 84,7 & 81,5 & 84,4 & 85,8 & 84.8 & 83.4 \\
\hline octobre & 89,4 & 83,2 & 86,9 & 86,7 & 86,8 & 88,3 & 87,3 & 85,1 & 86,6 & 86,8 \\
\hline novembre & 90,9 & 83.1 & 93,8 & 90,7 & 92,1 & 88,6 & 92,4 & 94,1 & 91,3 & 87,3 \\
\hline décembre & 91,9 & 86,4 & 94.5 & 90 & 91.9 & 89,5 & 92,5 & 91,1 & 90,1 & 90,1 \\
\hline janvier & 92,5 & 86,1 & 89,2 & 87.4 & 88,2 & 85,2 & 90 & 86,5 & 86,8 & 90 \\
\hline février & 87,5 & 78 & 85,7 & 87,5 & 85,1 & 82,9 & 86,9 & 83,6 & 82,7 & 88,8 \\
\hline marg & - & - & 86,8 & 87,3 & 87.3 & 87,1 & 88,4 & 85,8 & 85,1 & 91,3 \\
\hline
\end{tabular}


Il est, en fait, très délicat de mettre en évidence une action propre de la gestation sur un effectif d'animaux en élevage semi-extensif. On ne peut empêcher, en particulier l'interférence des variations saisonnières de l'alimentation. D'une manière plus générale, on ne peut pas toujours dissocier gestation et lactation. De plus, la simple comparaison entre animaux gestants et vides n'est pas expérimentalement parfaite, la protéinémie étant susceptible de varier suivant la période de la gestation.

\section{2) Modifications en cours de gestation.}

BALKOVA (1960) signale une diminution des PST à mesure que la gestation s'avance $(76,4 \mathrm{~g} / 1$ au $2 \mathrm{e}$ mois ef $68 \mathrm{~g} / /$ au $8-9 \mathrm{e}$ mols). En début de gestation, LARSON et KENDALL (1957) observent une diminution de la protéinémie. Cette diminution se produirait, au contraire, en fin de gestation d'après les observations de CABALLEROS ef VALLENAS (1958-1959) au Chili $(73,1 \mathrm{~g} / 1$ ef $72,4 \mathrm{~g} / \mathrm{l}$ respectivement 15 et 1 jour avant le part, pour une protéinémie normale estimée d̀ $80,1 \mathrm{~g} / \mathrm{l}$ ). Dans ce dernier cas, il est vrcisemblable que l'action de la mise-bas sur le taux de PST est prépondérante.

\section{3) Modifications dues à la porturition.}

II ressort des travaux de LARSON et Coll. (1954) que la protéinémie chule transitoirement au moment du part. Ces auteurs voient dans ce phénomène l'origine des œdèmes affectant certaines vaches. La diminution des PST est le reflet du passage des protéines sanguines dans le colostrum (LARSON et TOUCHBERRY, 1959). LARSON et KENDALL (1957) mentionnent deux maxima de protéinémie (4 semaınes avant et 11 semaines après le part) et deux minima (au moment de la mise-bas et 35 semaines après). Un fléchissement net des PST (59 $\mathrm{g} / \mathrm{l}$ ) par rapport aux chiffres trouvés 10 jours avant le part ( 75 à $80 \mathrm{~g} / \mathrm{l}$ ) est également rapporté par McGILLIVRAY (1959).

\section{j) Influence de la lactation}

Le niveau des PST est, d'après PERK ef LOEBL (1959), plus élevé chez la vache en lactation. Cef accroissement n'est pas toujours significatif (BOSTICCO, 1954 b). Au Sénégal, nous avons observé une relation inverse, sauf en fin de saison des pluies (tableau IV); mais, l'interprétation des données reste équivoque, la gestation venant se superposer à la lactation.

Par ailleurs, une corrélation existerait entre la protéinémie et la production lactée. POSTNIKOVA (1957) observe une teneur supérieure d̀ $85 \mathrm{~g} / \mathrm{l}$ pour un rendement de 3.000 à $4.000 \mathrm{I}$ de lait par an, ef inférieure à $85 \mathrm{~g} / \mathrm{l}$ pour une production supérieure à 6.0001 .

De plus, les variations de la protéinémie seraient parallèles à celles de la lactation : lorsque la quantité de lait produite passe en sept mois de $423,9 \mathrm{~kg}$ d̀ $218,8 \mathrm{~kg}$ par mois, les PST diminuent, de $74,5 \mathrm{~g} / \mathrm{l}$ à $65,5 \mathrm{~g} / \mathrm{l}$ de sérum (UL'YANOVA, 1957).

Cependant, ces relations n'ont pas été retrouvées par tous les auteurs. Ainsi, selon BOSTICCO (1954 b), il n'existerait pas de différence entre la protéinémie des bonnes et des mauvaises laitières.

La traite ne serait pas un facteur susceptible d'influencer la protéinémie (CHOPARD, 1954).

\section{k) Facteurs divers}

La deshydratation provoque, comme on pouvait s'y attendre, une augmentation sensibles des PST. (WEHMEYER, 1954 c). Cependant, la protéinémie et le volume globulaire ne varient pas toujours dans le même sens. Ainsi, en trois jours le taux passe de $77 \mathrm{~d} 84,8 \mathrm{~g} / \mathrm{l}$ et le volume globulaire de 36 à 44 p. 100. La reprise de l'abreuvement provoque, par contre une diminution rapide des PST tandis que le volume globulaire reste élevé.

L'exercice musculaire (deux heures de marche) ne perturbe pas la protéinémie (WEHMEYER, 1954 c). II est possible, cependant, et bien que la vérification n'est jamaıs été faite, qu'il n'en solt pas ainsi pour les animaux transhumants des pays tropicaux, en particulier en saison sèche.

En résumé, Il reste difficile de fixer une valeur précise de protéinémie normale pour les vaches adultes, tant en milıeu tempéré que tropical. Elle peut, en effet, subir de larges variations d'un animal à l'autre et peut être modifiée à la fols par des facteurs individuels (âge, race, gestation, lactation) et des facteurs d'environnement (saison, température, alimentation). L'exploitation des données fournies par le dosage des protéines sériques totales restera donc prudente, d'autant 
plus qu'elles représentent la somme de deux fractions (albumine et globulines) différentes tant par leur origine que par le rôle qu'elles jouent dans l'organisme.

\section{III. - L'ALBUMINE SÉRIQUE}

\section{a) L'albuminémie moyenne}

La moyenne générale des valeurs relevées sur une année à Sangalkam et à Bambey est, respectivement, de 30 et de $36,8 \mathrm{~g} / \mathrm{l}$. Ces valeurs sont proches de celles admises pour les pays tempérés, $31 \mathrm{~g} / \mathrm{l}$ (SPECTOR, 1956). Cependant, si on examine de plus près les données publiées (tableau 1), on constatera que l'albuminémie de la vache est très fluctuante, puisque, selon les auteurs et toujours pour l'animal normal, on trouve des moyennes variant de 16 (WALSHE et GILLES, 1962) à $44,3 \mathrm{~g} / /$ (GARNER, 1952) pour les pays tropicaux ef 25 (NILSSON ef ABERG, 1956) d̀ $43 \mathrm{~g} / \mathrm{l}$ (JACQUOT, LEBARS, SIMONNET, 1960) pour les pays tempérés. L'albuminémie peut donc varier, en moyenne, du simple au triple dans le premier cas et du simple au double dans le second.

\section{b) Les variations individuelles de l'albuminémie}

Les coefficients de variation, exprimés en pourcentage de la moyenne mensuelle correspondante, obtenus chez nos animaux, sont consignés dans le tableau $V$. Ils se répartissent entre 5,4 ef 16,5 p. 100 à Sangalkam $(9,2$ p. 100 en moyenne) et entre 5,5 et 10,3 p. 100 à Bambey (moyenne: 7,4 p. 100). La dispersion des données fournies par la littérałure est en moyenne de 12 p. 100 (tableau II). Si on admet une valeur de $30 \mathrm{~g} / \mathrm{l}$ pour l'albuminémie moyenne, on peut donc estimer, en première approximation, que la zone de normalıté va de 24 à $37 \mathrm{~g} / \mathrm{l}$ pour un animal pris isolément.

\section{c) Influence de la saison}

Au cours de l'année, on note, chez nos animaux une légère variation de l'albuminémie (tableau V). Elle se localise principalement au début de la saison sèche, de septembre à janvier ef se traduit par une augmentation de $7 \mathrm{~g} / \mathrm{l}$ à Sangalkam et de $4,5 \mathrm{~g} / \mathrm{l}$ à Bambey. Bien que ces modifications soient limıtées, leur signification statistique est évidente et on rencontre, ici à nouveau, une relation de type parabolique entre le temps et la teneur en albumine.

TABLEAU INO $\mathrm{V}$

Valeurs moyennes de l'albumine sérıque pour les troupeaux

de Sangalkam et de Bambey

\begin{tabular}{|c|c|c|c|c|}
\hline \multicolumn{3}{|c|}{ Troupeau S G K } & \multicolumn{2}{|c|}{ Troupeau B B } \\
\hline Mols & $\begin{array}{l}\text { Albunine } \\
g / 1\end{array}$ & $\begin{array}{c}\text { Coer'ficient } \\
\text { variation }\end{array}$ & Albumane & $\begin{array}{l}\text { Coefficient } \\
\text { variatzon }\end{array}$ \\
\hline $\begin{array}{l}\text { mars } \\
\text { avrıl } \\
\text { mai } \\
\text { Juin } \\
\text { juillet } \\
\text { août } \\
\text { septembre } \\
\text { octobre } \\
\text { novembre } \\
\text { décembre } \\
\text { janvier } \\
\text { février } \\
\text { mars } \\
\text { avril }\end{array}$ & $\begin{array}{l}29,9 \\
30,3 \\
29,3 \\
28,7 \\
27,6 \\
28,7 \\
27,3 \\
30,6 \\
32,7 \\
34,1 \\
34,1 \\
33,0\end{array}$ & $\begin{array}{c}8,2 \\
11,8 \\
12,2 \\
16,5 \\
11,3 \\
10,1 \\
6,6 \\
6,1 \\
5,4 \\
6,0 \\
8,0 \\
7,7\end{array}$ & $\begin{array}{l}37,6 \pm 2,6 \\
36,4 \pm 2,5 \\
36,8 \pm 3,8 \\
34,0 \pm 3,2 \\
35,4 \pm 2,8 \\
35,3 \pm 2,8 \\
35,2 \pm 2,4 \\
39,1 \pm 2,5 \\
39,9 \pm 2,7 \\
38,7 \pm 2,1 \\
36,6 \pm 2,3 \\
37,3 \pm 2,6 \\
36,4 \pm 3,0\end{array}$ & $\begin{array}{c}7 \\
7,0 \\
10,3 \\
9,5 \\
7,9 \\
8 \\
6,9 \\
6,4 \\
6,7 \\
5,5 \\
6,3 \\
6,9 \\
8,3\end{array}$ \\
\hline
\end{tabular}


ROSS (1960) a également mentionné une diminution de l'albumıne en fin de saison sèche ef une augmentation en hivernage, se poursuivant jusqu'en janvier. En milieu tempéré, WEHMEYER (1954 c) signale de légères fluctuations au cours de l'année; elles sont indépendantes des variations de la globulinémıe et du degré d'hydratation du sang.

\section{d) Influence de l'alimentation}

ROSS (1960) estime que le taux minimum d'albumine observé en fin de saison sèche est lié au fait que ses animaux sont nourris sur un pâturage pauvre. L'octroi d'un complément alimentaire augmente l'albuminémie.

Dans nos observations, bien que les animaux de Sangalkam aient reçu un supplément de tourteau d'arachide, l'albuminémie reste constamment et significativement inférieure à celle de Bambey. De plus, I'apparition de I'herbe n'entrave pas le mouvement général de descente observé en fin de saison sèche. II est possible que des aléas d'utilisation digestive au niveau du rumen diminuent la valeur du supplément distribué. Par ailleurs, CHOPARD (1954) signale que l'albumine sérique diminue lorsque les animaux passent du forn à l'herbe verte.

\section{e) Influence de la température}

L'albuminémie parât être sensible aux modifications de la température extérieure. Sur 9 animaux en stabulation, dans le courant d'une même journée, les résultats obtenus ont été les suivants :

$\begin{array}{ccc}\text { Heure } & \begin{array}{c}\text { Température } \\ \text { oC }\end{array} & \text { Albumine } \mathrm{g} / \mathrm{t} \\ \overline{-} & - & - \\ 9 & 21 & 25,8 \\ 11 & 24 & 27,2 \\ 15 & 27,9 & 28,8 \\ 17 & 28,6 & 31,8\end{array}$

Lorsque les écarts de température sont moins étendus, l'albuminémie ne se modifle pas significativement aınsi qu'il ressort des chiffres cidessous:

$\begin{array}{cc}\text { Température }{ }^{\circ} \mathrm{C} & \text { Albumine } \mathrm{g} / \mathrm{l} \\ - & - \\ 23,7 & 32,1 \\ 24,5 & 31,8 \\ 25,5 & 31,6 \\ 25,4 & 33,2\end{array}$

A la lumière de ces données, on ne peut envisager que les variations saisonnières soient purement d'ordre thermique, car elles évoluent en sens inverse de la température extérieure. En particulier, le taux d'albumine augmente en fin de saison sèche alors que la température ambiante se rafraîchit.

\section{f) Influence de l'âge}

On note, à Sangaikam, une différence entre l'albumınémie des animaux de trois ans et celle des sujets plus âgés. Celle-ci est constamment supérieure, mais la différence n'est significatıve que durant la deuxième moitié de la salson sèche et l'hivernage. Les chiffres deviennent très proches en début de saison sèche (tableau VI).

\section{g) Influence de la race}

Nous n'avons pas observé de différence significative entre l'albuminémı des Zébus et des N'Damas (tableau VI). Cependant, CONDY et CARR (1961) signalent, en Afrique du Sud, un taux d'albumine inférieur chez la vache N'Gami par rapport aux Afrikander ou aux Mashonas. Les vaches damascènes possèdent plus d'albumine que les croisements Holstein $x$ Hollandaise. (PERK et LOEBL, 1959 a) et les Angus plus que les Brahmas (ERWIN, 1960).

\section{h) Influence de la gestation}

L'action de la gestation sur le taux de l'albumine sérique paraît liée, dans nos observations, aux conditions d'environnement. A Sangalkam les vaches gestantes présentent une albuminémie supérieure à celle des vaches vides, alors qu'à Bambey, les albuminémies sonł indiscernables (tableau VI).

En milieu tropical ou tempéré, une relation inverse de celle que nous rapportons, a été signalée par différents auteurs. D'après ROSS (1960), en Nigeria, la gestation provoque une diminution non significative de l'albumine. Pour ROSSI (1957), l'albuminémie des vaches gravides est inférieure à celle des vaches vides.

Par ailleurs, l'albuminémie serait susceptible d'évolver en cours de gestation. De même que le taux des PST diminue à mesure que I'on se rapproche du part (de 80,6 à 69,3 g/l pour CALAPRICE, 1959), la proportion représentée par l'albumine va également en s'atténuant (42,8 ò 37,7 p. 100). CABALLERO et VALLENAS (1958 
TPBLEAU NO VI

Influence de l'âge, de la race, de la gestation et de la lactation sur l'albumine, en $g /$ litre

\begin{tabular}{|c|c|c|c|c|c|c|c|c|c|c|c|c|c|c|}
\hline \multirow{3}{*}{ Mois } & \multicolumn{4}{|c|}{ Influence de $I^{\prime}$ âge sur $I$ ' albuminemie $g / 1$} & \multicolumn{2}{|c|}{ Influence de la race } & \multicolumn{4}{|c|}{ Influence gestation } & \multicolumn{4}{|c|}{ Influence lactation } \\
\hline & \multirow{2}{*}{$\begin{array}{l}\text { vaches de } \\
3 \text { ans }\end{array}$} & \multirow{2}{*}{$\begin{array}{l}\text { vaches de } \\
7 \text { à } 9 \text { ans }\end{array}$} & \multirow{2}{*}{$\begin{array}{l}\text { vaches de } \\
4 \text { à } 6 \text { ans }\end{array}$} & \multirow{2}{*}{$\begin{array}{l}\text { vaches de } \\
10-13 \text { ans }\end{array}$} & \multirow[b]{2}{*}{ Zébus } & \multirow[b]{2}{*}{$N^{\top}$ Dana } & \multicolumn{2}{|c|}{ SGK } & \multicolumn{2}{|c|}{ BB } & \multicolumn{2}{|c|}{ SGK } & \multicolumn{2}{|c|}{ BB } \\
\hline & & & & & & & G+ & $6-$ & $\overline{\mathrm{G}+}$ & G- & $\mathrm{Lt}$ & $\bar{L}$ & $\overline{\mathrm{L}+}$ & I- \\
\hline mara & 24,6 & 29,9 & - & - & - & - & 29,8 & 30 & 38,7 & 37 & - & - & - & - \\
\hline avril & 26,6 & 30,3 & 38,4 & 37,5 & 36,4 & 38 & 30,5 & 30,2 & 36,8 & 34,4 & 30,5 & 30 & 37,4 & 39,8 \\
\hline mat & 25,3 & 29,3 & 36,1 & 35,8 & 37.7 & 35,9 & 29.8 & 28,8 & 36 & 37,2 & 28,2 & 30.7 & 35,5 & 37 \\
\hline jutn & 25,4 & 28,7 & 36,5 & 36 & 38,6 & 56,3 & 31,5 & 29 & 33,7 & 34 & 28,4 & 30,6 & 36,2 & 36,7 \\
\hline juallet & 26,9 & 27,6 & 34,9 & 32,6 & 34,6 & 33,8 & 29,9 & 24 & 35,8 & 35 & 27,2 & 30 & 33,5 & 34,6 \\
\hline aost & 25,1 & 28,7 & 35,5 & 35,5 & 35 & 35,6 & 30.3 & 28,4 & 35,3 & 35,5 & 28,2 & 30,2 & 35,5 & 35,5 \\
\hline septembre & 25,7 & 27,3 & 34,7 & 36,2 & 35,1 & 35,4 & 28 & 26,5 & 35.3 & 35,4 & 27,4 & 27 & 36,1 & 33.7 \\
\hline octobre & 30,3 & 30,6 & 35,7 & 34,8 & 34,8 & 35,3 & 32,3 & 29,3 & 39 & 39,3 & 30,3 & 31,5 & 35,6 & 33,9 \\
\hline novembre & 30,8 & 32,7 & 38,5 & 40 & 39 & 39,1 & 33,5 & $3 \uparrow, 7$ & 39.9 & 39,2 & 31,7 & 33,5 & 39,9 & 36.8 \\
\hline décembre & 34 & 34,1 & 39,4 & 40 & 40,3 & 39,7 & 34,8 & 33,3 & 39,2 & 37.9 & 33,3 & 34,8 & 39,5 & 39.9 \\
\hline janvier & 33.3 & 34,1 & 38,6 & 38,5 & 39,1 & 38,5 & 34,9 & 32,8 & 36,7 & 36,6 & 33,2 & 35 & 38,5 & 38.7 \\
\hline février & 30,9 & 33 & 36,9 & 36,3 & 36,5 & 36,6 & 34,3 & 33,6 & 36,9 & 36,9 & 31,7 & 34,3 & 36,9 & 36,2 \\
\hline IIarg & - & - & 37,7 & 36 & 38,6 & 37 & - & - & 36,8 & 35 & - & - & 37,3 & 36,5 \\
\hline
\end{tabular}


1959) signalent aussi des taux d'albumine très faibles de l'ordre de $17 \mathrm{~g} / \mathrm{l}$, en fin de gestation. Par contre, au moment de la mise bas, le taux d'albumine reste pratiquement inchangé par rapport au taux observé 4 semaines avant, d'après LARSON et KENDALL (1957).

Nous nous trouvons done en face de conclusions contradictoires. En fait, il paraît difficile de mettre en évidence d'une manıère satisfaisante l'action de la gestation lorsqu'on veut l'observer à l'échelle d'un troupeau tout venant. II faudrait que tous les stades de gestation soient représentés par un nombre égal d'animaux, constituant des effectifs suffisants. De plus, il est impossible de dissocier gestation ef lactation dans la plupart des cas.

\section{i) Influence de la lactation}

PERK et LOEBL (1959 b) ont signalé une augmentation de l'albumine chez les vaches en lactation. Ce phénomène s'observe sur les vaches de Sangalkam, mais non sur celles de Bambey (tableau VI).

Le taux d'albumine pourrait aussi dépendre de la production laitière (BALKOVA, 1960). UI'YANOVA (1957) note une albuminémie de $51,7 \mathrm{~g} / \mathrm{l}$ pour une production de $423,9 \mathrm{~kg} /$ mois et, sept mois plus tard, $33 \mathrm{~g} / \mathrm{l}$, pour une production mensuelle de $218,8 \mathrm{~kg}$ de lait.

En résumé, si on peut admettre, en première approximation que l'albuminémie de la vache est de 30 à $35 \mathrm{~g} / \mathrm{l}$ de sérum, on doit, cependant, garder présent à l'esprit que cette donnée est susceptible de varier dans de très larges mesures, le principal facteur perturbateur étant sans doute d'ordre alimentaire.

\section{IV. — LES GLOBULINES SÉRIQUES}

\section{a) La globulinémie moyenne}

Le taux mayen enregistré sur une année à Sangalkam est de $55,4 \mathrm{~g} / \mathrm{l}$ et de $49,9 \mathrm{~g} / \mathrm{l}$ à Bambey. Les moyennes fournies par la littérature s'échelonnent entre $31,8 \mathrm{~g} / \mathrm{l}$ (PERK et LOEBL, 1959) et $60.4 \mathrm{~g} / \mathrm{l}$ (GARNER, 1952). Le chiffre retenu par SPECTOR (1956) est de $38 \mathrm{~g} / \mathrm{l}$ pour les climats tempérés. Nos valeurs sont donc relativement élevées, ce qui paraît être de règle en milieu tropical. CABALLERO et VALLENAS (1958-
1959) enregistrent de 55,5 d̀ $58,1 \mathrm{~g} / \mathrm{l}$ au Chili chez des vaches de race européenne. CONDY et CARR (1961) signalent $56 \mathrm{~g} / \mathrm{l}$ pour les vaches N'Gami, en Afrique du Sud. En Nigeria, la globulinémie du Zébu Fulani monte à 47,2 g/l en octobre (ROSS, 1960) et WALSHE et GILLES (1962) notent, en Gambie, un taux élevé (46 d̀ $57 \mathrm{~g} / \mathrm{l})$ malgré une concentration en PST fable.

\section{b) Les variations individuelles de la globulinémie}

Exprimé en pourcentage de la valeur moyenne correspondante, l'écart type varie à Sangalkam de 3,9 d̀ 10 p. 100 (moyenne : 7,6 p. 100) et de 8,2 à 10,3 p. 1 co à Bombey (moyenne: 9,3 p. 100) (tableau VII). Bien que ces valeurs témoignent d'une dispersion appréciable des données individuelles, elles sont moins larges que la plupart de celles relevées dans la bibliographie, plus particulièrement en milieu tropical, pour lequel les coefficients de variation fluctuent entre 15 et 20 p. 100. La glabulinémie d'un animal donné est donc susceptible de trouver sa place dans une zone relativement vaste sans sortır de la « normale ».

\section{c) Les variations saisonnières}

La globulınémie subit, au cours de l'année, des variations limıtées (tableau VII), allant de 51,1 à $58,8 \mathrm{~g} / /$ à Sangalkam et de 47,1 à $52,6 \mathrm{~g} / \mathrm{l}$ à Bambey. La concentration augmente en fin de saison sèche et atteint un maximum au milieu de la salson des pluies; puis un minimum survient et se situe pour les deux troupeaux en septembre. Le taux de globuline s'accroît ensuite pendant le premier tiers de la saison sèche (soit jusqu'en novembre-décembre) puis rejoint les valeurs minimales que nous venons de signaler, au cours du deuxième tiers de cette période. A Bambey, l'évolution en salson sèche est ajustable à deux régressions paraboliques portant chacune sur quatre mois. Par analogie, la même représentation a été adoptée pour les mouvements trimestriels d'évolution en fin de saison sèche.

La teneur en globulines est plus élevée à Sangalkam qu'à Bambey, sans doute en raison des conditions d'environnement. La ferme de Sangalkam est située en zone subguinéenne et les atteintes parasitaires y sont en particulier plus nombreuses qu'à Bambey. 
TABLEAU No VIl. - Variations sassonnières de la globulinémı ef coefficient de variation

\begin{tabular}{|c|c|c|c|c|}
\hline \multirow{2}{*}{ Mois } & \multicolumn{2}{|c|}{ Troupeau de Bambey } & \multicolumn{2}{|c|}{ Troupeau de Sangalkam } \\
\hline & Globulines $\mathrm{E} / \mathrm{I} \pm$ & $\begin{array}{l}\text { Coefficient de } \\
\text { variation }\end{array}$ & globulines $\mathrm{g} / \mathrm{l} \pm$ & $\begin{array}{l}\text { coefficient de } \\
\text { variation }\end{array}$ \\
\hline marg & - & - & $52.6 \pm 4.8$ & 9,0 \\
\hline avril & $47,1 \pm 4,7$ & 10 & $51,1 \pm 4,1$ & 8,1 \\
\hline mai. & $47,2 \pm 4,3$ & 9 & $53.5 \pm 4.5$ & 8,5 \\
\hline nivנ & $52,6 \pm 5,4$ & 10,3 & $54,6 \pm 3,4$ & 6,3 \\
\hline juillet & $51,1 \pm 5$ & 9.7 & $55,6 \pm 3,8$ & 6,9 \\
\hline goût & $52,2 \pm 5$ & 9,6 & $57,7 \pm 2,2$ & 3,9 \\
\hline septembre & $48.6 \pm 4.5$ & 9,2 & $53,1 \pm 3,4$ & 6.3 \\
\hline octobre & $50,8 \pm 4,2$ & 8,2 & $58,8 \pm 4,7$ & 8,0 \\
\hline novembre & $52,2 \pm 5$ & 9,5 & $58,2 \pm 3,9$ & 6,7 \\
\hline décembre & $51,1 \pm 4,5$ & 8,8 & $57,8 \pm 5,0$ & 8,7 \\
\hline Janvier & $48,8 \pm 4, ?$ & 8,3 & $58,4 \pm 5,8$ & 10 \\
\hline février & $47.9 \pm 4,7$ & 9,9 & $54,5 \pm 4,7$ & 8,6 \\
\hline mars & $49,9 \pm 4,8$ & 9,6 & - & - \\
\hline
\end{tabular}

En Nigeria, ROSS (1960) a observé une glabulinémı plus élevée en hivernage $(47,2 \mathrm{~g} / \mathrm{l})$ qu'en saison sèche $(40,8 \mathrm{~g} / \mathrm{l})$. II en est de même en Gombie (WALSHE et GILLES, 1962) où l'on relève $46 \mathrm{~g} / \mathrm{l}$ en novembre et $57 \mathrm{~g} / \mathrm{l}$ en août.

\section{d) Influence de l'alimentation}

On possède peu de renseignements sur l'action des facteurs nutritionnels sur la production des globulines chez la vache. Cependant, ROSS (1960) remarque que le taux le plus faible coïncide avec la saison sèche, au moment où l'alimentation est la plus précaire. Dans nos observations, le minimum observé en septembre reste inexpliqué ; l'apport azoté esł suffisant à cette époque de l'année. On peut cependant envisager que sa dégradation digestive se fasse dans des conditions défavorables.

\section{e) Influence de la température ambiante}

Le taux des globulines est pratiquement inchangé par des variations thermiques capables de provoquer une augmentation de l'albumine ef des protéines sériques totales. Les résultats suivants ont été obtenus à Dakar, sur 9 animaux en stabulation et dans le courant d'une même journée.

$\begin{array}{cc}\text { Température o } C & \text { Globulines } \mathrm{g} / \mathrm{l} \\ - & - \\ 21 & 51,4 \\ 24 & 51,6 \\ 27,9 & 50,3 \\ 28,6 & 52,8\end{array}$

f) Influence de l'âge

A mesure que l'âge augmente, le taux de globulines augmente progressivement, sauf chez le touf jeune animal pour lequel la prise du colostrum provoque un accroissement passager. Le maximum est atteint à l'âge de cinq ans chez le Zébu (GARNER, 1950) ou de quatre ans, en milieu tempéré (LARSON et TOUCHBERRY, 1959). Nos observations confirment dans l'ensemble ces données (tableau VIII).

\section{g) Influence de la race}

La bibliographie apporte peu de renseignements sur l'influence de la race. PERK et LOEBL (1959) constatent un taux plus élevé chez les Hollandaises que chez les Damascènes. La globulınémie des vaches N'Gami est supérieure à celle des Mashona ou des Afrikander (CONDY ef CARR, 1961). Dans le troupeau de Bambey, pour notre part, nous avons constaté entre les Zébus et les N'Dama une différence de quelques grammes par litre en faveur de ces dernières (tableau $\mathrm{VIII}$ ). 
TABLEAU No VIII. - Influence de l'âge, de la race, de la gestation sur la globulinémie des vaches des troupeaux de Sangalkam ef de Bambey (grammes par litre)

\begin{tabular}{|c|c|c|c|c|c|c|c|c|c|c|c|c|c|c|}
\hline \multirow{3}{*}{ Mois } & \multicolumn{4}{|c|}{ Influence de I'Agge } & \multicolumn{2}{|c|}{ Influence de la race } & \multicolumn{4}{|c|}{ Influence de Ia gestation } & \multicolumn{4}{|c|}{ Influence de la lactation } \\
\hline & \multicolumn{2}{|r|}{ SGK } & \multicolumn{2}{|c|}{ BВ } & \multirow{2}{*}{ Zébus } & \multirow{2}{*}{ N1 Dara } & \multicolumn{2}{|c|}{ SGK } & \multicolumn{2}{|c|}{$\mathrm{BB}$} & \multicolumn{2}{|c|}{ SGK } & \multicolumn{2}{|c|}{$\mathrm{BB}$} \\
\hline & 3 ans & $7-9$ ans & $4-6$ ans & $10-13$ ans & & & $G+$ & $G$ & $G+$ & G- & $\mathrm{L}+$ & L- & $\mathrm{Lt}$ & In \\
\hline mars & 46,7 & 52,6 & - & - & - & $=$ & 52,1 & 52,9 & - & - & 54,1 & 47,2 & & \\
\hline avril & 47,4 & 51,1 & 49 & 45,5 & 47,1 & 46,9 & 50,9 & 51,4 & 45,9 & 48,9 & 51,9 & 49,6 & 47,1 & 47,4 \\
\hline mai & 47,1 & 55,5 & 47,7 & 46 & 48,1 & 46,9 & 54,6 & 52,2 & 46 & 48,4 & 53,9 & 53 & 46,7 & 47,6 \\
\hline juin & 49,6 & 54,6 & 51,1 & 53,5 & 53.7 & 52,2 & 58,5 & 52,7 & 52,1 & 52.7 & 54,2 & 57,9 & 51,7 & 54,2 \\
\hline juillet & 52 & 55,6 & 50,9 & 52,2 & 49,8 & 51,5 & 58,5 & 53.5 & 52 & 50,2 & 55,3 & 57,6 & 51,2 & 52,4 \\
\hline soût & 52 & 57,7 & 51,3 & 54.3 & 50,6 & 52,7 & 59 & 56,5 & 53,3 & 50,7 & 56,8 & 60,7 & 52 & 54.7 \\
\hline septembre & 45,5 & ' 53,1 & 49,3 & 49,2 & 46,4 & 49.3 & 52,8 & 53,4 & 49,1 & 50,3 & 52,8 & 54,1 & 49,1 & 49.7 \\
\hline octobre & 52,9 & 58,8 & 50,9 & 52,0 & 48,5 & 51,4 & 56,5 & 60,6 & 52 & 49,7 & 60,7 & 54 & 50,4 & 53,9 \\
\hline novembre & 52,3 & 58,2 & 52,2 & 53,8 & 49,6 & 52,9 & 55,7 & 61,3 & 53,6 & 51,8 & 61,3 & 55,7 & 52,8 & 53,2 \\
\hline décembre & 52,4 & 57,8 & 50,6 & 54,4 & 49,2 & 52,2 & 54,5 & 61,9 & 52,6 & 51,1 & 61,9 & 54,5 & 52,1 & 52,2 \\
\hline janvier & 52,8 & 58,4 & 48,8 & 50,7 & 46,1 & 49.7 & 57,4 & 60 & 51 & 48,6 & 61,4 & 55,3 & 48,9 & 51,2 \\
\hline février & 47,2 & 54,5 & 47,6 & 49,5 & 46,4 & 48,5 & 53,6 & 53,1 & 50,2 & 47 & 57 & $51 ; 9$ & 46,7 & 51,2 \\
\hline marg & - & - & 49,6 & 50,8 & 48,7 & 50,2 & - & - & 51,5 & 48,9 & - & & 48,6 & 52,0 \\
\hline
\end{tabular}

SGK = Sangelkam $-\mathrm{BB}=$ Bambey $-\mathrm{Gt}=$ gestantes $-\mathrm{G}=$ = non gestantes $-\mathrm{It}=$ en lactation - Ir $=$ tarieg 


\section{h) Influence de la gestation}

D'une manière générale, la gestation paraît s'accompagner d'une augmentation de la globulinémie. D'après ROSSI (1957) le pourcentage des protéines sanguines totales représenté par les globulines est augmenté $(68,2$ p. 100 contre $56,7 \mathrm{p}, 100$ ). Comme les PST n'ont pratıquement pas changé $(77,2 \mathrm{~g} / /$ contre $79,2 \mathrm{~g} / \mathrm{l})$ on peut en déduire que les globulines se sont accrues en valeur absolue.

ROSS (1960) décrit un fait comparable, mais les différences observées ne sont pas significatives. En Israel, PERK ef LOEBL (1959 b) rapportent également un accroissement du taux des globulines et, en particulier, des gamma-globulines.

II est possible que les conditions d'environnement interfèrent. A Bambey, l'action de la gestation n'apparaît plus en saıson sèche et à Sangalkam, elle n'est notable qu'c̀ la fin de la saison sèche et au début de l'hivernage. Elle s'inverse à partir de septembre (tableau VIII).

En cours de gestation, CALAPRICE (1959) considère que les différentes globulines ne participent pas également à la diminution générale des PST. Les alpha et bêta-glabulınes augmenteraient en pourcentage, tandis que les gammaglobulines suivraient une évolution inverse.

Les phénomènes les plus apparents se rencontrent au moment du part. Par rapport aux concentrations relevées quatre semaines avant la mise bas, les alpha-globulınes baissent de 20 p. 100 et l'ensemble bêta-gamma-globulines de 46 p. 100 . Après le part, l'augmentation, mesurée au bout de 11 semaines est de 49 p. 100 pour les alpha et de 15 p. 100 pour l'ensemble bétagamma-globulınes (LARSON et KENDALL, 1957). Ces globulines sont drainées vers la mamelle et passent dans le colostrum.

Plus récemment, DIXON et Coll. (1961) estıment que les modifications des globulines sériques au moment du vêlage sont dues aux variations seules des gamma-globulines (1), qui chutent au moment du part. Leur transfert vers le colostrum est cent fois plus important que celui de la séro-albumıne. La quantité de gamma-globulines

(1) Les déterminations sont faites par électrophorèse sur papier ou por des méthodes immunochimiques utilisant un sérum de lapin antı-gammaglobulınes bovines. La deuxième méthode donne toujours des résuliats supérieurs. dans le colostrum, à la mise bas, est sensıblement égale à la quantité de globulines ayant quitté le sang pendant l'ante-partum. Ceci tend à prouver l'origine uniquement sérique des antcorps du colostrum. Ce fait se trouve confirmé par les examens histologiques, immunohistochimiques et la microscopie électronique (FELDMAN, 1961). On ne trouve, en effet, dans la mamelle qu'un nombre très faible de cellules d'origine plasmatique capables de produire des anticorps. II est donc peu probable que la mamelle soit le siège d'une synthèse active de ces globulines.

\section{i) Influence de la lactation}

L'action de la sécrétion lactée sur les globulines n'apparaît pas nettement au vu des résultats que nous avons obtenus. On note une hyperglobulinémie passagère chez les vaches en lait de Sangalkam en début de saison sèche, alors que le phénomène inverse est observé à Bambey (tableau VIII).

Il est possible que la confusion provienne de l'instabilité des globulines sériques au cours de la période de tarissement, valeur qui est prise comme base de comparaison. DIXON et Coli. (1961) distinguent deux séquences pendant la périade de repos mammaire. Durant les 4 à 6 premières semaines qui suivent l'arrêt de la lactation, le prélèvement des globulines sériques par la mamelle est pratıquement inexistant, ce qui entraîne une augmentation de 30 p. 100 des glabulines gamma par rapport au niveau de fin de lactation. Dans une deuxième phase, débutant trois semaines avant le part, la gammaglobulinémie dımınue de 40 p. 100 par rapport au maximum précédent. Pour une vache de $500 \mathrm{~kg}$. $680 \mathrm{~g}$ environ de gamma-globulines quitteraient ainsi le sang et constitueraient la plus grande partie des gamma-globulınes contenues dans la mammelle au moment de la mise bas (718 g). L'examen du graphıque publié par ces auteurs montre que la quantité totale de gammaglobulines dans le sérum sanguin est d'environ $1.300 \mathrm{~g}$ en fin de lactation, $1.600 \mathrm{~g}$ trois semaines avant le part et $950 \mathrm{~g}$ à la mise bas. La gammaglobulinémie varie donc de \pm 25 p. 100 suivant la période du tarissement que l'on envisage. On conçoit donc, que dans ces conditions, il devienne malaisé de mettre en évidence une influence éventuelle de la lactation en comparant sımple- 
ment la globulinémie des vaches en lait et des vaches taries.

Sı le prélèvement de gamma-globulines par la mamelle est très sensible à l'approche du vêlage, il ne s'en poursuit pas moins pendant le reste de la lactation (DIXON et Coll., 1961) et on pourrait concevoir que le niveau globulinémique dépende de l'intensité de la production laitière, le taux se révélant plus faible chez les fortes productrices. C'est ce qu'il semble ressortir des observations de POSTNIKOVA (1956) : la globulinémie des vaches donnant de 3.000 à 4.000 I par an dépasse $31 \mathrm{~g} / \mathrm{l}$ tandis qu'elle oscille entre 27 ef $29 \mathrm{~g} / \mathrm{l}$ pour des productions supérieures ou égales à 6.000 I par an. UL'YANOVA (1957) signale une augmentation des globulines sériques (de 22,8 à $31,9 \mathrm{~g} / /$ ) quand, au cours d'une même lactation, la production mensuelle passe de $423,9 \mathrm{~kg}$ à $218,8 \mathrm{~kg}$ de lait. Cependant, BALKOVA (1960) relève des variations parallèles des alpha ef gamma-globulines sanguines et du rendement en lait. Enfin, les travaux de BOSTICCO (1954 b) ne font pas ressortir de différence significative entre les globulinémies des bonnes et des mauvaises laitières.

Au demeurant, DIXON et Coll. (1961) estiment que la perte quotidienne de globulines par la mamelle diminue rapidement après le vêlage et reste constante à partır du deuxième mois de lactation. Simultanément, la concentration sanguine en gamma-globulines dans le sang augmente considérablement par rapport à la misebas puis diminue lentement. La relation entre production laitière et globulinémie n'est donc pas univoque. De plus le phénomène se complique si on falt intervenir des variations possibles de l'intensité de la synthèse des gamma-globulines, qui se trouverait augmentée de 10 à $20 \%$ en début de lactation.

Pour nous résumer, et en sımplifiant au maximum, disons que la globulinémie augmente de près de $50 \%$ par rapport au niveau enregistré au vêlage, pendant les deux premiers mois de la lactation. Elle diminue ensuite lentement jusqu'au tarissement où le taux est encore supérieur de $25 \%$ à la concentration observée d̀ la naissance du veau.

En conclusion, bien que la dispersion des chiffres moyens relevés soit assez large, la globulinémie moyenne des animaux en milieu tropı- cal oscille autour de 50 à $55 \mathrm{~g} / \mathrm{l}$ et celle des vaches de milieu tempéré autour de $40 \mathrm{~g} / \mathrm{l}$.

Les valeurs individuelles peuvent s'éloigner fortement de ces chiffres, en particulier sous l'influence de facteurs tels que la saison, l'âge, la race, l'état de gestation et de lactation.

\section{V. - LE RAPPORT ALBUMINE/GLOBULINE}

\section{a) La valeur moyenne du rapport $A / G$}

L'albuminémie, en moyenne, représente 55 , 4 p. 100 des globulines à Sangalkam et 74,7 p. 100 à Bambey. Ces deux valeurs sont significativement différentes et reflètent les disparités que nous avons déjà rencontrées à propos des globulines.

Le rapport A/G paraît, au demeurant très variable lorsqu'on examine les chiffres déjà publiés (tableau I). Ceux-ci s'étendent de 0,31 (CABALLERO et VALLENAS, 1958-1959) d̀ 1,22 (PERK ef LOEBL, 1959) et il paraît à première vue impossible de définir une valeur moyenne de référence. On peut, cependant tourner la difficulté, en faisant le rapport des valeurs que nous avons considérées comme normales pour l'albumine $(30 \mathrm{~g} / \mathrm{l})$ et pour les globulınes $(40 \mathrm{~g} / \mathrm{l}$ en milieu tempéré et $50 \mathrm{~g} / /$ en climat tropical). On obtient alors 0,75 pour les pays tempérés et 0,60 pour les pays chauds. Cet artifice ne doit pas faire oublier cependant que le rapport $A / G$ est susceptible de varier de 1 à 4 chez des lots d'animaux consıdérés comme normaux.

\section{b) Les variations individuelles (tableau IX)}

L'étendue des variations individuelles doif être soulignée. Le coefficient de variation, tel que nous l'avons défini aux chapitres précédents, est de 13 p. 100 de la valeur moyenne correspondante; ce qui revient à dire qu'à l'échelle d'un animal pris isolément, le rapport $A / G$ peut se situer approximativement entre 40 et 70 p. 100 pour Sangalkam, 55 et 95 p 100 à Bambey, 35 à 115 p. 100 en milieu tempéré et 30 à 90 p. 100 en milieu tropical (1).

(1) Ces valeurs sont obtenues en ajoutant ou en retranchant deux fois l'écart type d̀ la valeur moyenne. Ceci implique une distribution normale des données, c'est-àdire une répartition des $A / G$ liée uniquement au hasard. Cette supposition est a priori erronée puisque les deux termes du rapport dépendent de facteurs d'environnement et de facteurs indıviduels. Les chiffres que nous mentionnons n'ont donc qu'une valeur purement indicative. 
TABLEAU No IX. - Influence de la saison sur le rapport albumina/globuline

\begin{tabular}{|c|c|c|c|c|}
\hline \multicolumn{3}{|c|}{ Troupeau de Sangalkam } & \multicolumn{2}{|c|}{ Troupeau B日 } \\
\hline Mols & $\frac{A}{G} \pm \sigma$ & $\begin{array}{c}\text { Coefficient } \\
\text { de } \\
\text { variation }\end{array}$ & $\frac{A}{G} \pm \sigma$ & $\begin{array}{c}\text { Coefficient } \\
\text { de } \\
\text { variation }\end{array}$ \\
\hline mara & $0,57 \pm 0,09$ & 15,5 & - & - \\
\hline avril & $0,60 \pm 0,10$ & 16,9 & $0,81 \pm 0,10$ & 12,3 \\
\hline $\max$ & $0.55 \pm 0.10$ & 18,3 & $0,78 \pm 0,09$ & 11,6 \\
\hline nin & $0,52 \pm 0,07$ & 14,4 & $0,71 \pm 0,13$ & 18,4 \\
\hline juillet & $0.50 \pm 0.05$ & 10,4 & $0,67 \pm 0,10$ & 14,6 \\
\hline aodt & $0,50 \pm 0,05$ & 9,2 & $0,68 \pm 0,09$ & 13,2 \\
\hline septembre & $0,51 \pm 0,05$ & 9,9 & $0.74 \pm 0,09$ & 12,6 \\
\hline octobre & $0,53 \pm 0,07$ & 12,5 & $0,70 \pm 0,09$ & 12,5 \\
\hline novembre & $0,57 \pm 0,05$ & 9,7 & $0.76 \pm 0,08$ & 11,2 \\
\hline décembre & $0,60 \pm 0,07$ & 11,2 & $0,78 \pm 0,09$ & 11,4 \\
\hline janvier & $0,59 \pm 0,08$ & 13,6 & $0,80 \pm 0,08$ & 10,5 \\
\hline février & $0,61 \pm 0,08$ & 13,6 & $0,77 \pm 0,09$ & 11,8 \\
\hline mars & - & - & $0,76 \pm 0,10$ & 12,9 \\
\hline
\end{tabular}

\section{c) Les variations saisonnières}

Les deux termes du rapport A/G se modifiant au cours de l'année, il est normal de constater une évolution saisonnière de ce rapport. A Sangalkam, il varie de 49,5 à 61 p. 100 en diminuant régulièrement en fin de saison sèche et pendant I'hivernage ; à partir de septembre, il s'accroît jusqu'à la fin du premier tiers de la saison sèche suivante et se stabilise aux environs de 60 p. 100 L'ensemble des points figuratifs se répartit le long d'une fonction parabolique symétrique (tableau $(X)$.

A Bambey, an note une évolution de même type, bien que moins régulıère. De 81 p. 100 en fin de saison sèche, le rapport passe à 67 p. 100 en juillet, atteint près de 80 p. 100 en janvier. A la fin de la saison des pluies, on observe une ascillation non significafıve du tracé (tableau IX).

L'écart maximum observé est donc, dans les deux cas, de 20 p. 100 de la valeur la plus basse.

\section{d) Influence de la température}

Dans ce domaine, les variations de $A / G$ découlent de celles que nous avons observées pour l'albumine lorsque des écarts de température suffisants sont mis en cuvre. L'albumine augmentant alors que les globulines restent stationnaires, le rapport A/G s'accroît.
Sur nos 9 animaux gardés en stabulation nous avons obtenu :

$\begin{array}{cc}\text { Température o } & \text { A/G } \\ - & - \\ 21,3 & 0,51 \\ 24,1 & 0,54 \\ 27,9 & 0,57 \\ 28,6 & 0,61\end{array}$

L'augmentation, pour une augmentation de température de $7,3^{\circ} \mathrm{C}$, est done de $10 \mathrm{p} .100$ en valeur absolve et de 20 p. 100 de la valeur la plus basse du rapport. II est vraisembiable que la température extérieure soit un des facteurs responsables des modifications sassonnières de $A / G$.

\section{e) Influence de l'âge}

Si on compare, à Sangalkam, les animaux de 3 ans aux vaches plus âgées, on remarque que le rapport $A / G$ des premières est significativement inférieur en fin de saison sèche. II est du même ordre de grandeur pendant l'hivernage et devient significativement supérieur pendant les deux premiers tiers de la saison sèche suivante (tableau $X$ ). A quelques points de détail près, on observe un phénomène analogue à Bambey. 
TABLEAU $\boldsymbol{X}$

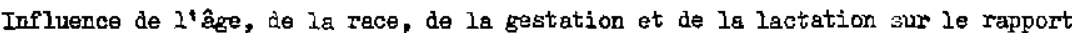
$A / G$ exprimé on pour cent.

\begin{tabular}{|c|c|c|c|c|c|c|c|c|c|c|c|c|c|c|}
\hline \multirow{3}{*}{ Mois } & \multicolumn{4}{|c|}{ Influence do l'âge } & \multirow{2}{*}{\multicolumn{2}{|c|}{$\begin{array}{l}\text { Influence } \\
\text { de la race }\end{array}$}} & \multicolumn{4}{|c|}{ Influence de la gestation } & \multicolumn{4}{|c|}{ Influence de la lactation } \\
\hline & \multicolumn{2}{|c|}{ SGK } & \multicolumn{2}{|c|}{ BB } & & & \multicolumn{2}{|c|}{ SGK } & \multicolumn{2}{|c|}{$\mathrm{BB}$} & \multicolumn{2}{|c|}{ SGK } & \multicolumn{2}{|c|}{ BB } \\
\hline & 3 ans & 7 ans & $4-6$ ans & $10-13$ ans & Zóbus & $N^{+}$Dama & G+ & G- & $\mathrm{G+}$ & $G$ & $\mathrm{~L}+$ & I- & $\mathrm{I}+$ & $\mathrm{L}$ \\
\hline Mars & 52 & 57 & - & - & - & - & 57 & 57 & - & - & 55 & 65 & - & - \\
\hline Avril & 56 & 60 & 80 & 83 & 78 & 81 & 61 & 60 & 85 & 76 & 59 & 61 & 80 & 86 \\
\hline Mai. & 53 & 55 & 76 & 78 & 79 & 77 & 55 & 55 & 80 & 72 & 56 & 58 & 77 & 79 \\
\hline Juin & 52 & 52 & 73 & 68 & 73 & 71 & 54 & 52 & 70 & 73 & 52 & 53 & 71 & 68 \\
\hline Juillet & 52 & 50 & 69 & 63 & 70 & 66 & 51 & 48 & 65 & 69 & 59 & 52 & 66 & 66 \\
\hline soût & 49 & 49,5 & 70 & 66 & 70 & 68 & 51 & 48 & 68 & 70 & 49 & 49 & 69 & 65 \\
\hline Septembre & 56 & 56 & 73 & 74 & 76 & 74 & 53 & 50 & 74 & 71 & 52 & 49 & 76 & 69 \\
\hline Octobre & 58 & 58 & 70 & 67 & 72 & 69 & 58 & 49 & 68 & 71 & 50 & 59 & 72 & 63 \\
\hline Novembre & 59 & 59 & 74 & 75 & 79 & 74 & 60 & 52 & 73 & 76 & 52 & 60 & 76 & 69 \\
\hline Décembre & 65 & 65 & 78 & 74 & 82 & 77 & 64 & 54 & 76 & 77 & 54 & 64 & 77 & 77 \\
\hline Janvier & 63 & 63. & 79 & 76 & 85 & 78 & 63 & 55 & 77 & 78 & 55 & 63 & 79 & 76 \\
\hline Février & 66 & 66 & 78 & 74 & 80 & 76 & 64 & 56 & 73 & 78 & 56 & 66 & 79 & 71 \\
\hline Marg & - & - & 77 & 71 & 81 & 74 & - & - & 72 & 76 & - & - & 77 & 70 \\
\hline
\end{tabular}

$\mathrm{SGK}=$ SangaIkam $-\mathrm{BB}=$ Bambey $-G+$ = Gestantes $-G=$ non Gestantes - Lt = Lactation $-\mathrm{I} r=$ taries 
En milieu tempéré, BOSTICCO (1954 a) observe une diminution du rapport entre 3 mois ef 3 ans. Elle est due à une diminution de l'albumine et une augmentation des gamma globulines.

\section{f) Influence de la race}

Le rapport $A / G$ des Zébus est significativement supérieur, pour l'ensemble de l'année, à celui des taurins (tableau $X$ ). Une intervention de la race a également été signalée, en Israël, par PERK et LOEBL (1959 a). Ces auteurs relèvent un rapport de 0,84 pour les Holstein $X$ Hoblandaises et de 1,22 chez les damascènes. Pour celles$\mathrm{ci}$, le taux plus élevé de l'albumine serait à l'origine d'une rétention plus forte de l'eau de l'organisme et, par conséquent, d'une meilleure résistance à la chaleur et à la soif. Cette hypothèse est réfutée, en Afrique du Sud, par CONDY et CARR (1961) qui constatent une résistance élevée à la deshydratation, bien que le rapport A/G de leurs animaux soit inférieur à 1, et que l'albuminémie soit inférieure à celle des vaches damascènes.

\section{g) Influence de la gestation}

A Sangalkam, le rapport A/G des gestantes est constamment supérieur à celui des vaches vides, alors que le phénomène inverse s'observe, le plus souvent, à Bambey (tableau X). ROSSI (1957), en milieu tempéré, note une diminution du rapport chez les vaches gravides.

\section{h) Influence de la lactation}

Le comportement de nos deux troupeaux diffère sensiblement, à nouveau, au cours de l'année, Si, dans les deux cas, les rapports ne sont pas significativement différents en fin de scison sèche. par contre, A/G des vaches en lait est supérieur à celui des vaches taries à Bambey pour le reste de l'année, tandis qu'on observe un phénomène inverse à Sangalkam, et uniquement à partir de lo fin de l'hivernage. Nous avons déjà signalé le caractère aléatoire des comparaisons entre vaches taries et vaches en lactation, compte tenu des fluctuations importantes de la globulinémie pendant la période de tarissement.

En résumé, le rapport $A / G$ subit de larges variations portant à la fois sur les moyennes de troupeau ef sur les valeurs individuelles. Les facteurs d'environnement paraissent jouer un rôle important et sont capables de modifier l'influence des facteurs d'ordre physıologique.

\section{VI. - DISCUSSION}

Le falt marquant, rencontré tout au long de cette étude, est la dispersion des valeurs mentionnées, qu'il s'agisse des valeurs individuelles ou des moyennes.

Dans le premier cas, on peut concevoir un étalement assez large des données, ces fluctuations étant lıées aux caractères propres des animaux examinés. On a vu que cet éventail était de l'ordre \pm 20 p. 100 de la valeur moyenne pour les différentes classes de protéines et sans que l'augmentation des effectifs soumis aux observations diminue sensiblement cette marge. If faut vraisemblablement voir, dans cette dispersion, l'intervention, à l'échelle de chaque individu, des différents facteurs physiologiques et le fait que les coefficients de variation soient pratiquement indépendant du nombre des animaux mis en jeu laisse à penser que pour un troupeau donné les modalités d'intervention de ces facteurs sont sans doute très proches (proportion relative de sujets d'âges différents, pourcentage de vaches gestantes et vides, en lactation ef taries...).

On peut être plus intrigué par la dispersion des valeurs moyennes, les animaux étant considérés comme normaux dans tous les cas. Les valeurs extrêmes sont séparées par un écart exprimé en pourcentage de la moyenne minima observée - de 50 p. 100 pour les protéines sériques totales, de 200 à 250 p. 100 pour l'albumine, de 100 p. 100 pour les globulines. Il est donc vraisemblable que le terme d'animal normal n'a pas la même significajion pour tous les auteurs.

Ainsi, on peut, à titre d'exemple, calculer la pression oncotique des protéines sériques, dans le cas des animaux de Gambie (WALSHE et GILLES, 1962), en utilisant la formule de GOVAERTS :

$$
P(\mathrm{~mm} \mathrm{Hg})=5.54 \mathrm{~A}+1.43 \mathrm{G}
$$

$A=$ concentration en albumine (g pour $100 \mathrm{ml}$ )

$G=$ concentration en globulines ( $g$ pour $100 \mathrm{ml}$ ).

On obtient alors : $15,4 \mathrm{~mm} \mathrm{Hg}$ en novembre, $16.1 \mathrm{~mm} \mathrm{Hg}$ en janvier, $18,4 \mathrm{~mm} \mathrm{Hg}$ en mai ef $18,7 \mathrm{~mm} \mathrm{Hg}$ en août. Si on admet, avec BEST et 
TAYLOR que la filtration au niveau des capillaires s'effectue sous une pression d'environ $10 \mathrm{~mm} \mathrm{Hg}$, on constatera ici que la force de filtration est de 1,5 à 2 fois supérieure au niveau normal. Il doit donc s'ensulvre inéluctablement, une fuite liquidienne vers les tissus, entraînant un état hydroémique qui signe habituellement les états de dénutrition.

Or, ces auteurs soulignent que leurs animaux sont entretenus dans les conditions habituelles de l'élevage en brousse. La question est donc de savoir si, en climat tropical, dans les conditions «normales» d'exploitation, les animaux sont physiologiquement normaux. Au vu des chiffres précédents, Il ne le semble pas.

Le problème de la référence à laquelle doi† être comparée la protéınémie mesurée chez une vache de brousse reste donc posé, En toute logique, la confrontation devrait être réalisée avec des chiffres obtenus avec des animaux placés dans des conditions identiques. On ne saurait, pour se faire, s'adresser à un troupeau pris au hasard. Nous avons vu le rôle joué par les conditions d'environnement et, en élevage extensif de milieu tropical, on doit malheureusement constater que tous les degrés de la misère existent. Une solution consisterait à déterminer la protéinémie moyenne de l'effectif auquel appartient le sujet examiné, ce qui compliquera, en tout état de cause, une méthode d'investigation que l'on désire, avant tout, simple.

De même, il conviendra d'être prudent dans l'interprétation des résultats fournis par les bovins d'élevage semi-extensif (les animaux de station expérimentale, par exemple). II importe, en particulier, de bien situer l'animal vis-à-vis des facteurs extérieurs et des facteurs physiologiques. Peut-on le faire, actuellement, avec toute la rigueur désirable? A notre sens, il ne le semble pas et des études complémentares seront nécessaires avant d'y parvenir. II est pratiquement impossible de chiffrer l'action des facteurs de variation, et dans bien des cas, l'intervention de ceux-ci est plus suspectée que rigoureusement démontrée. Des renseignements précis sur le rôle exact joué par le rationnement, la température extérieure, l'abreuvement, la gestation, etc... manquent encore et des expériences de type factoriel mériteraient d'être entreprises.
Pour le moment, nous ne pouvons choisir qu'entre l'erreur et la confusion. Encore fallait-il être dûment averti de cette malencontreuse alternative.

\section{CONCLUSIONS}

10 La teneur en protéines totales du sérum de vache adulte varie de 64,5 à $89,2 \mathrm{~g} / \mathrm{l}$ en valeur moyenne pour les animaux tropicaux. La dispersion des valeurs individuelles autour de la moyenne est de l'ordre de \pm 15 à 20 p. 100 .

Le niveau de la protéinémie dépend de la saison, vraisemblablement par l'intermédiaire des fluctuations qualitatives et quantitatives de l'alimentation ainsi que par les modifications de la température extérieure. Le taux des PST augmente jusqu'à l'âge de cinq ans. Il peut être influencé par la race et tend à s'accroître pendant la gestation. L'influence de la lactation reste controversée, La deshydratation augmente la protéinémie, mais l'exercice musculaire limité parâ̂t sans effet.

$2^{\circ}$ On peut admettre, en première approximation, que l'albuminémie moyenne est de 30 à $35 \mathrm{~g} / \mathrm{l}$. Cependant, cette donnée est susceptible de larges variations. La dispersion des valeurs individuelles est de l'ordre de \pm 20 p. 100 autour de la moyenne correspondante. Des modifications saisonnières sont signalées, ainsi qu'une intervention de l'âge et de la race. Les conditions d'environnement modifient l'action de la gestation tandis que la lactation se traduit par une augmentation de la teneur en albumıne.

$3^{\circ}$ Bien que la dispersion des valeurs moyennes publiées soit relativement large, la globulinémie moyenne peut être estimée à $50-55 \mathrm{~g} / \mathrm{l}$ en milieu tropical et à $40 \mathrm{~g} / \mathrm{l}$ en milieu tempéré. Les variations individuelles sont importantes. Les. fluctuations saisonnières restent limitées ef une certaine indifférence vis-à-vis de la température extérieure est notée. La globulinémie augmente jusqu'à l'âge de cinq ans. Son taux dépend de la race. II est augmenté par la gestation ef la lactation ef diminue fortement à la mise-bas.

40 Le rapport albumine/glabuline se révèle très fluctuant. On peut, cependant admettre une valeur moyenne approximative de 0,75 en milieu tempéré et de 0,60 en climat tropical, sans omettre que, dans ce dernier cas, elle peut varier dans la proportion de 1 à 4 . Les variations individuelles représentent 25 p. 100 de la 
moyenne correspondante. Le rapport A/G dépend de la saison, de la température, de l'âge, de la race, de la gestation et de la lactation.

$5^{\circ}$ La grande variabilité des chiffres moyens de protéinémie tient, à côté de facteurs d'environnement ou individuels non contrôlés, aux différentes significations que l'on peut donner au terme d'animal « normal ».

\section{Institut d'Elevage et de Médecine Vétérnaire des Poys tropicaux.}

Laboratoire National de Recherches Vétérinaires Dakar (Sénégal).

\section{SUMMARY}

\section{Proleınemia in the Cow}

The percentage of total proteins, both abumin and globumin in the blood serum of the cow is a figure that varies considerably, both from one animal to another as well as from one herd to the next.

This is due to the influence of factors dependent on the animals themselves frace, age, gestation, lactation), factors of environment (season, temperature, (ood), but also, in a tropical environment, the different meanings attributable to the term «normal animal».

As far as the total proteins are concerned the figures have been estimated as varying from between 64,2 to $89,2 \mathrm{~g} / \mathrm{l}$ for tropical animals; for the albumin, an average value of 30 to $35 \mathrm{~g} / /$ and for the globulins 50 to $55 \mathrm{~g} / /$ in a tropical enviranment and $40 \mathrm{~g} / 1$ in a temperate country.

The albumin/globulin ratio under these conditions would then have an approximale value of 0,75 for a temperate climate, and 0,60 for a tropical climate with possibly wider variations.

\section{RESUMEN}

\section{La Proteinemia de la vaca}

El termino medio de las proteinas totales, de la albúmına y de las globulinas del suero sanguíneo de la vaca es un dato muy variable, de un animal a otro $y$ de un rebano a otro.

Esto proviene de la intervención de factores propios a los animales (raza, edad, gestación, lactación) de factores de media ambiente (estación, temperaiura, alimentación) pero tambıén, en medio ambiente tropical, de diferentes significaciones que se pueden dor a la palabra «animal normal ».

Se puede retener, para las proteinas totales, cifras variando entre 64,5 y $89,2 \mathrm{~g} / \mathrm{l}$ para los animales tropicales; en cuanto a la albúmina, un valor medio de 30 a $35 \mathrm{~g} / /$ y en cuanto a las glabulinas de 50 a $55 \mathrm{~g} / \mathrm{l}$ en medio ambiente tropical y de $40 \mathrm{~g} / \mathrm{l}$ i en país templado.

La proporcion albúmina/globulina en estas condiciones tendrá un valar aproximalivo de 0,75 en medio ambiente templado y de 0,60 en clima tropical, con grandes variaciones posibles.

\section{BIBLIOGRAPHIE}

1. BALDAEV, S. N. - Changes in the amount of total protein and residual nitrogen and in the activity of blood protease of lactating cows. Trudy Buryat Mongol. Zoovet. Inst. 1958, 13, 31-35, in Chem. Abstr. 1960, 54.14.402 d.

2. BALKOVA, T. M. - Belki syrovotky krovi korovi netelej (Protéines sériques des vaches et des génisses). Trudy Buryot Zoovet. Inst. 1960, 14, 183-189, in Nutr. Abst. Rev., 1961, $31,1214$.
3. BARNES, J. E., JEPHCOTT, B. R. - Biochemical sludies of cattle in the Northern Territory. Il. Seasonal variation of serum inorganic phosphorus, haemoglobin plasma protein and haematocrit in the Alice Spring District. Austr. Vet. J. 1959, 35, 280-283.

4. BEST, C. H., TAYLOR, N. B. - The physiological basis of medical practice. Baltimore, Williams \& Wilkins, $1950,5 \mathrm{e}$ ed., 1 vol., $1330 \mathrm{p}$. 
5. BOSTICCO, A. - La frazioni protidiche elletroforetiche nello siero di sangue di Bos taurus L. in rapporto all'eta. Ann. Fac. Med. Vet. Torino, 1954 (a) 4, 273-283.

6. BOSTICCO A. - Ricerche ed osservazioni sulle frazioni nello siero di sangue di femmine (Bos taurus L.) in particolari condizioni d'utilizzazione zootechnica. Ann. Fac. Med. Vet. Torino, 1954 (b) , 4, 291-296.

7. BOSTICCO, A. - La frazioni protidiche nello siero di Bos taurus L., determinate con l'elletroforesi su carta in rapporto al gruppo etnico di appartenenza. Ann. Fac. Med. Vet. Troino, 1954, 4, 286-289.

8. CABALLERO, C. A., VALLENAS, P. A. - Estudios de la proteinas del suero sanguineo en relacion con la prenez avanzada y el parto, en vacunos. Rev. Fac. Med. Vet. Lima 19581959, I3-|4, 169-181.

9. CALAPRICE, A. - Behavior of the serum electrophoretogram of the cow during pregnancy and the first week of normal puerperium. Acto Med. Vet., 1959, 5, 287-298, in Chem. Abst., 1960, 54, 229161.

10. CHOPARD, P. - Bestimmung der Eiweissfraktionnen des Blutserums bei des Haustieren der Papierelektrophorese unter Berucksichtigung verschiedener Faktoren. Ztschr. Tierzucht. Zuchtungsbiol. 1954, 63, 21-52.

11. CONDY, J. B., CARR W. R. - Observations on the serum proteins of Afrikander, Mashona, and Ngami cattle. Vet. Rec., 1961, $73,91-93 ; 100$

12. DIMOPOULOS, G. T. - Polysaccharide and protein relationships of bovine normal serum Am. J. Vet. Res, 1961, 22, 986-989.

13. DIVEN, R. H., PAGE, H. M., ERWIN, E. S., ROUBICEK, C. B. - Effect of environmental temperature on diurnal variation of blood constituents in the bovine, Am. J. Physiol, 1958, 88-90, 195.

14. DIXON, F. J., WEIGLE, W. O., VAZQUEZ, J.J. - Metabolism and mammary secretion of serum proteins in the cow. Lab. Invest. $1961,10,216-237$.

15. DUKES, H. H. - The physiology of domesfic animals. London, Baillière, Tyndall \& Cox, 1955, 7 e éd., 1 vol., 1020 p.

16. ERWIN, E, S. - Comparative serum constituents in Brahman and Angus vows. J. Darry Sc. 1960, 43 ; 98-99.
17. FALASCHINI, A., BIONDO, G. - Modificazione protidemiche nella specie bovina in seguito al lavoro. Atti. Soc. Ital. Sci. Vet., 1954, 8, 391-394.

18. FELDMAN, J. D. - Fine structure of the cow's udder during gestation and Iactation Lab. Invest. 1961, 10, 238-255.

19. de FRANCISCIS, G., ZACCHI, B., BERNI$N$, L. - Le proteine plasmatiche in bovine gravide. Nota preliminare. Boll., Soc. Itol., Biol. Sper., 1957, 33, 1560-1561.

20. GARNER, J. J. - Physiological variations in serum proteins in caftle, Nature, 1950, 165, 896-897.

21. GARNER, $R, J$, - Variations in serum protein levels in cattle. J. comp. 1952, 92, 279286.

22. GERUSOV, D. M. - Biochimical indexes of Cattle in relation to age and state of pregnancy. Trudy Buryat Mongol Zoovet Inst. 1958, 13, 363-365, in Chem. Abst. 1960, 54, 17. 616 a.

23. HEYNDRICKX, G, V. - investigations on the lipids, proteins, lipo-and glycoproteins of udder lymph and plasma in cattle. Quart. J. Exp. Physiol., 1959, 44, 264-270.

24. JACQUOT, R., LE BARS, H., SIMONNET, $H$. - Données générales sur la nutrition et l'alimentation. Vol. Il. Paris, Baillère, 1960. 1 vol., 963 p.

25. JONES, E. R. - Chemical composition of the blood of Ankole and Zebu Cattle in Uganda Vet. Rec. 1943, 55, 128-129.

26. $L A B O U C H E, C l$. Méthode d'appréciation de la séparation des fractions obtenues par microélectrophorèse en milieu liquide, Ann. Inst. Pasteur Paris, 1962 (a), 102, 556-560.

27. LABOUCHE, Cl. - Méthode mathématique d'interprétation quantitative des électrophorèse, Ann. Inst. Pasteur Parıs, 1962 (b), 102, 561-566.

28. LABOUCHE, Cl, - Calcul d'erreurs dans l'interprétation quantifative des électrophorèses de sérum des Bovidés domestiques, Ann. Biol. Anim., Bioch. Bioph. 1962 (c) 2, 251-263.

29. LABOUCHE, $\mathrm{Cl}$ - - Bases mathématiques d'une interprétation éventuelle des séparations électrophorétiques incomplètes. Ann. Biol. Anim. Bioch. Bioph., 1962 (d) 2, 319-328. 
30. LABOUCHE, Cl. - Essai d'utilisation d'une méthode mathématique d'inferprétation quantitative des séparations électrophorétiques incomplètes. Ann. Biol. anim. Bioch. Bioph. 1962 (e) 2, 329-334.

31. $L A B O U C H E, C l$., AMALOU, P, - Variations physiologiques des protéines totales du sérum de Vache adulte en milieu tropical, C. R. Soc. Biol. 1963 (a) 157, 604-609.

32. LABOUCHE, Cl., AMALOU, P., CALVET, $H$. - Variations physiologiques de l'albumine sérique de la Vache adulte en milieu tropical, C. R. Soc. Biol., 1963 (b), I57, 14721475.

33. LABOUCHE, $C l$, AMALOU, P., CALVET, $H$. - Variations physiologiques des globulines sériques de la Vache adulte en milieu tropical, C. R. Soc. Biol., 1963 (c), I57, 1784-1786.

34. LARSON, B. L. - Transfer of specific blood serum proteins to the lacteal secretions near parturition. J. Dairy Sc. 1958, 4I, 1033.

35. LARSON, B. L., KENDALL, K. A. - Changes in specific blood serum proteins levels associated with parturition in the bovine. J. Doiry Sc., 1957, 40, 659-666.

36. LARSON, B. L., ROLLERI, E. D., KENDALL, K. A. - Changes in bovine blood proteins associated with parturition, J. Dairy Sc. 1954, 37, 662

37. LARSON, B. L., TOUCHBERRY, R. W. Bllood serum proteins level as a function of age. j. Animal Sc.,-1959, 18, 983-990.

38. Mc GILLIVRAY, W. A. - The origin of carotenoids, vitamin $A$ and tocopheral in colostrum, N. Z. J. Agric. Res., 1959, 2, 694-701.

39. MENON, U. K., REDDY, M. V. R. - Analysis of serum proteins of Indian cows by paper electrophoresis, Indian Vet. J., 1960, 37, 388-392.

40. MONTEMAgNO, G., AGRESTi, A. - Quadro elltroforetico del siero di sangue proteine liproproteine nei bovini e negli equini, Acto Med. Vet., 1957, 3. 35-46.

41. MORRIS, B., COURTICE, F. C. - The protein and lipid composition of the plasma of different animal species determined by zone electrophoresis and chemical analysis. Quatr. J. Exp. Physiol., 1955, 40, 127-137.

42. MULLICK, D. N., PAL, A. K. - Studies on the composition of the blood of farm animals in India. I. A study of some haematological and chemical constituents. Ind. Vet. J., 1943, 13, 146-149, cité par SEN. K. C. (1953).
43. NILSON, T., ABERG, B. - Proteins and protein bound carbohydrates in normal bovine serum. Nord. Vet. 1956, 8, 975-982.

44. PERK, K., LOEBL, K. - A comparative study on the sera proteins and lipids in two breeds of cattle. Brit. Vet. J., 1959 (d), II5, 411-415.

45. PERK, K., LOEBL, K. - Die Serumeiweissfraktionen im Rinderblut - eine chemische und papierelektrophoretische Studie, Schw. Arch. f. Tierhlk., 1959 (b), 101, 548-556.

46. POSTNIKOVA, A. N. - Total proteins, albumins and globulins in the blood serum of high producing cows. Trudy Moskov. Vet. Akad., 1956, II, 42-51.

47. ROSS, J. G. - Norma serum albumen values in Nigerian Zebu Cattle, Vet. Rec. 1960, 72, 159-160, 161.

48. ROSSI, A. - Comportamento del quadro elletroforetico del siero di bovine sterili e gravide in rapporto al tipo d'alimentazione, Clin. Vet. 1957, 80, 241-243.

49. SEN., K. C. - Animal nutrition research in India. London, Mac Milan, 1953, I vol, 370 p.

50. SPECTOR, W. S. - Handbook of biological data. Philadelphia, London, Saunders, 1956, 1 vol., 584 p.

51. SPISNI, D., FRATESCHI, T. L. - Content of tryptophan in the blood serum of beef cattle at varying ages, Ann. Fac. Med. Vet. Univ. Piso, 1959, 12, 323-330, in Chem. Abstr., 1961, 55, 2839 b.

52. UL'YANOVA, G. K. - Some peculiarities in composition of cow's blood proteins in relation to productivity. Dokl. Mosk. Sel' skokhoz Akod. im K. A. Timiryazevo, Nauch. Konf. 1957, 2, 68-75, in Chem. Abstr. 1960, 54, $10,096 \mathrm{c}$.

53. WALSHE, S. L. H., GILLES, H. M. - Haematological and biochemical observations on a herd of Gambian Cattle. J. comp. Path., 1962, 72, 439-449.

54. WEHMEYER, P, - Concentration of plasma proteins in the ox. I. Individual differences Nord. Vet. Med. 1954 (a) 6, 717-736.

55. WEHMEYER, P. - Variation in the composition of the blood in cows during thrist, after intake of water and on hungring. Acta Path. Microb Scand. 1954 (b), 34, 518-520.

56. WEHMEYER, P. - Concentration of plasma proteins in the ox. Il. Variation in composition of the blood in the individual animals. Nord. Vet. Med., 1954, (c), 6, 118-874. 